OPEN ACCESS

Edited by:

Cirino Botta

Cosenza Hospital, Italy

Reviewed by:

Jaume Mora,

Hospital Sant Joan de Déu

Barcelona, Spain

Michael Allen Sheard,

Children's Hospital of Los Angeles,

United States

*Correspondence:

Taofeek K. Owonikoko

towonik@emory.edu

Specialty section:

This article was submitted to Cancer Molecular Targets and

Therapeutics,

a section of the journal

Frontiers in Oncology

Received: 11 January 2020 Accepted: 20 May 2020

Published: 07 July 2020

Citation:

Nazha B, Inal $C$ and Owonikoko TK (2020) Disialoganglioside GD2

Expression in Solid Tumors and Role as a Target for Cancer Therapy.

Front. Oncol. 10:1000. doi: 10.3389/fonc.2020.01000

\section{Disialoganglioside GD2 Expression in Solid Tumors and Role as a Target for Cancer Therapy}

\author{
Bassel Nazha ${ }^{1}$, Cengiz Inal ${ }^{2}$ and Taofeek K. Owonikoko ${ }^{1 *}$ \\ ${ }^{1}$ Department of Hematology and Medical Oncology, Emory University School of Medicine, Atlanta, GA, United States, \\ 2 Salem Veterans Affairs Medical Center, Salem, VA, United States
}

Gangliosides are carbohydrate-containing sphingolipids that are widely expressed in normal tissues, making most subtypes unsuitable as targets for cancer therapy. However, the disialoganglioside GD2 subtype has limited expression in normal tissues but is overexpressed across a wide range of tumors. Disialoganglioside GD2 can be considered a tumor-associated antigen and well-suited as a target for cancer therapy. Disialoganglioside GD2 is implicated in tumor development and malignant phenotypes through enhanced cell proliferation, motility, migration, adhesion, and invasion, depending on the tumor type. This provides a rationale for targeting disialoganglioside GD2 in cancer therapy with the development of anti-GD2 monoclonal antibodies and other therapeutic approaches. Anti-GD2 monoclonal antibodies target GD2-expressing tumor cells, leading to phagocytosis and destruction by means of antibody-dependent cell-mediated cytotoxicity, lysis by complement-dependent cytotoxicity, and apoptosis and necrosis through direct induction of cell death. Anti-GD2 monoclonal antibodies may also prevent homing and adhesion of circulating malignant cells to the extracellular matrix. Disialoganglioside GD2 is highly expressed by almost all neuroblastomas, by most melanomas and retinoblastomas, and by many Ewing sarcomas and, to a more variable degree, by small cell lung cancer, gliomas, osteosarcomas, and soft tissue sarcomas. Successful treatment of disialoganglioside GD2-expressing tumors with anti-GD2 monoclonal antibodies is hindered by pharmacologic factors such as insufficient antibody affinity to mediate antibody-dependent cell-mediated cytotoxicity, inadequate penetration of antibody into the tumor microenvironment, and toxicity related to disialoganglioside GD2 expression by normal tissues such as peripheral sensory nerve fibers. Nonetheless, anti-GD2 monoclonal antibody dinutuximab (ch14.18) has been approved by the U.S. Food and Drug Administration and dinutuximab beta (ch14.18/CHO) has been approved by the European Medicines Agency for the treatment of high-risk neuroblastoma in pediatric patients. Clinical trials of anti-GD2 therapy are currently ongoing in patients with other types of disialoganglioside GD2-expressing tumors as well as neuroblastoma. In addition to anti-GD2 monoclonal antibodies, anti-GD2 therapeutic approaches include chimeric antigen receptor T-cell 
therapy, disialoganglioside GD2 vaccines, immunocytokines, immunotoxins, antibody-drug conjugates, radiolabeled antibodies, targeted nanoparticles, and T-cell engaging bispecific antibodies. Clinical trials should clarify further the potential of anti-GD2 therapy for disialoganglioside GD2-expressing malignant tumors.

Keywords: GD2, ganglioside, monoclonal antibody, cancer therapy, neuroblastoma, small cell lung cancer, dinutuximab, clinical trials

\section{INTRODUCTION}

Gangliosides are carbohydrate-containing sphingolipids (glycosphingolipids) composed of a ceramide (usually sphingosine, a long-chain amino alcohol, attached by an amide group to a fatty acid core that varies in chain length from $\mathrm{C} 18$ to $\mathrm{C} 20$ ) bound to $\mathrm{N}$-acetylneuraminic acid (Neu5Ac) or another sialic acid (an acidic carbohydrate with a ninecarbon backbone) linked to one or more monosaccharide units (1-3). Standard ganglioside nomenclature begins with the letter G ("ganglioside"), followed by the letter M, D, T, $\mathrm{Q}, \mathrm{P}, \mathrm{H}$, or S referring to mono-, di-, tri-, quatra- (tetra-), penta-, hexa-, and septasialogangliosides, respectively, based on the number of sialic acid residues (2-4), and ending with the numbers 1,2 , or 3 indicating the order of ganglioside migration on thin layer chromatography (5). As an example, the ganglioside GD2 subtype comprises two sialic acid residues (i.e., a disialoganglioside) linked to three monosaccharide units (Figure 1).

Intracellular synthesis of gangliosides begins with formation of the ceramide core, followed by addition of the monosaccharide unit(s) and translocation to the plasma membrane $(6,7)$. Attached to the outer plasma membrane by their ceramide moiety, gangliosides interact laterally with membrane proteins and other membrane lipids to regulate the responsiveness of signaling molecules and to function as mediators and modulators of signal transduction (8). Their monosaccharide units extend into the extracellular space, where they have

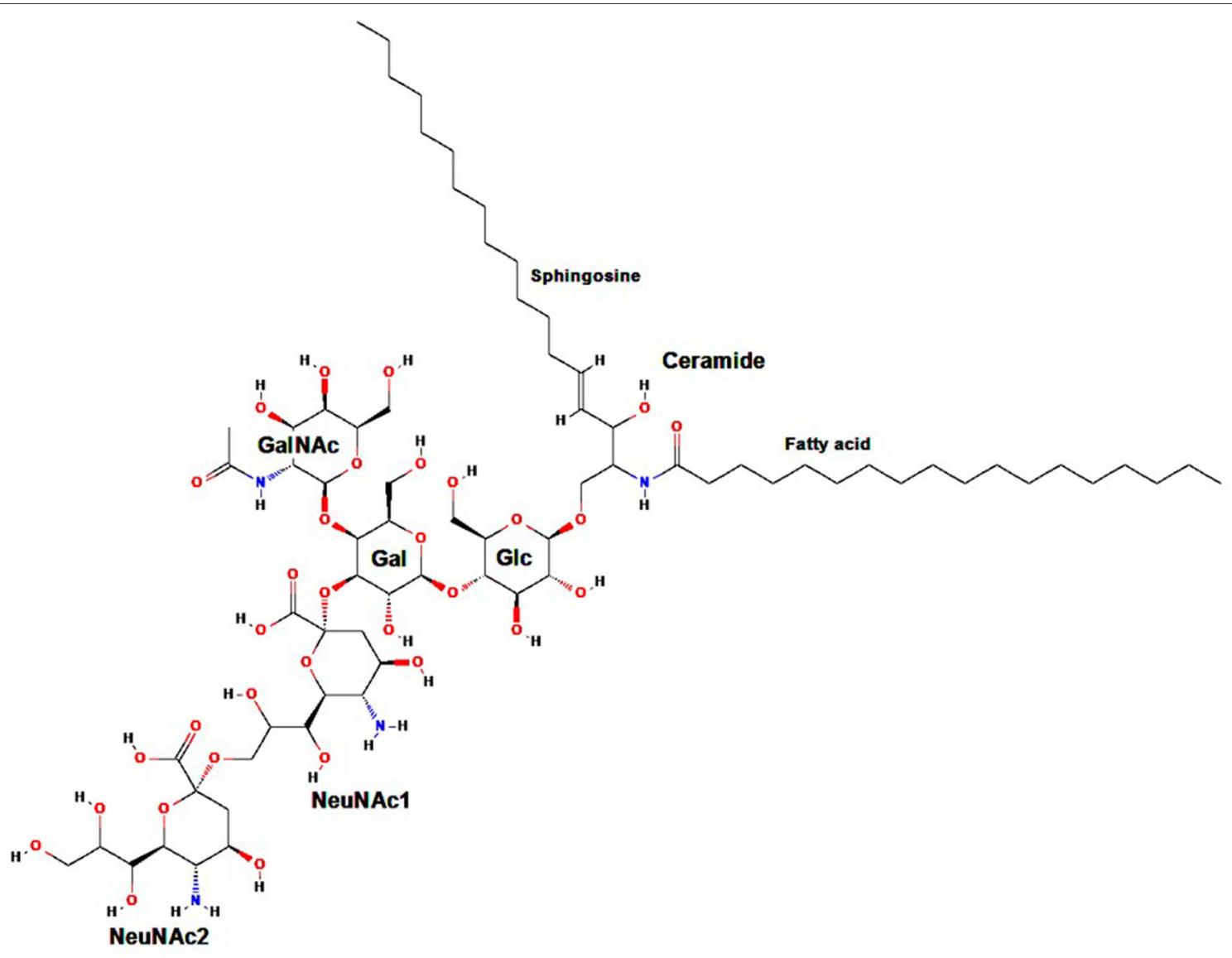

FIGURE 1 | Molecular structure of GD2. Gal, galactose; GalNAc, N-acetylgalactosamine; Glc, glucose; NeuNAc, N-acetylneuraminic acid. Adapted from: Ganglioside GD2. NIH. U.S. National Library of Medicine. National Center for Biotechnology Information. Available at: https://pubchem.ncbi.nlm.nih.gov/compound/53481124. 
antigenic properties and facilitate cell-cell recognition and adhesion (8-10).

Gangliosides such as GM3, GM2, GM1, and GD1 are expressed across many normal human tissues (6, 10-12) and appear to have multiple biological functions, particularly cell recognition and regulation of membrane-bound signaling proteins such as epidermal growth factor receptor and vascular endothelial growth factor receptor (10, 13). In contrast, expression of disialoganglioside GD2 in normal tissues is limited essentially to the central nervous system, peripheral sensory nerve fibers, dermal melanocytes, lymphocytes, and mesenchymal stem cells $(12,14,15)$. Although disialoganglioside GD2 appears to participate in cell signaling, its function in normal cellular physiology has not been fully elucidated and therefore is not well-understood (16). In cancer, however, disialoganglioside GD2 contributes to enhanced tumor cell proliferation, motility, migration, adhesion, and invasion, depending on the tumor type, and confers resistance to apoptosis (12, 17-20).

This review will focus on disialoganglioside GD2 as a target for cancer therapy and various approaches under investigation aimed at GD2-expressing tumors.

\section{DISIALOGANGLIOSIDE GD2 ANTIGEN AS A THERAPEUTIC TARGET IN CANCER}

\section{Restricted Tumor Expression}

Although many gangliosides are expressed by a wide range of human tumor cells, generally they are not considered potential targets for cancer therapy because of their extensive expression by normal tissues $(6,10,11,21)$. Given its very limited expression in normal human tissues and extensive expression by a number of tumors, disialoganglioside GD2 can be considered a tumor-associated antigen $(14,22,23)$ and thus is valuable as a primary target for cancer immunotherapy (15). Indeed, the U.S. National Cancer Institute ranked disialoganglioside GD2 twelfth among 75 potential targets for anti-cancer therapy in 2009 based on potential therapeutic effect, degree of expression, immunogenicity, and percentage of antigen-specific cells (24).

\section{Neuroblastoma}

GD2 is the major ganglioside present in human neuroblastoma cell lines, is synthesized in large quantity by the great majority of primary untreated neuroblastomas and is detectable in plasma and tumor tissue of patients with neuroblastoma regardless of the disease stage $(25,26)$. More rapid progression of neuroblastoma and lower patient survival appear to be associated with higher circulating tumor-derived disialoganglioside GD2 levels at the time of diagnosis (27); circulating GD2 levels decrease in response to therapy and increase again in patients with recurrent disease (28).

GD2 expression by neuroblastoma cells can be detected using different technologies including enzyme-linked immunosorbent assay (ELISA), immunoperoxidase staining of frozen tissues, and high-pressure liquid chromatography/tandem mass spectrometry $(25,29)$. Schulz et al. identified GD2 serum levels $>26 \mathrm{ng} / \mathrm{mL}$ (mean of controls \pm 3 S.D.) by ELISA in
21 of 23 pre-chemotherapy neuroblastoma patients (91.3\%), six of whom had levels $>1,000 \mathrm{ng} / \mathrm{mL}$ (30). Two of the six patients presented with stage III disease and four with stage IV disease. Of six patients with stage I or II disease, none had GD2 serum levels $>100 \mathrm{ng} / \mathrm{mL}$. Disialoganglioside GD2 was expressed at high tissue concentrations in $100 \%$ of 36 cases of primary untreated neuroblastoma as reported by $\mathrm{Wu}$ et al. (31). Untreated neuroblastomas were of all stages (I-IV) and thus GD2 expression was stage-independent. Similarly, Cheung et al. reported a series of eight cases of neuroblastoma, all of which expressed GD2 as determined by in vitro immunostaining and/or in vivo radioimaging (32). Schengrund and Shochat identified disialoganglioside GD2 in 45 of 53 childhood neuroblastomas $(84.9 \%)$ (33). In the series reported by Sariola et al., 28 of 30 pediatric neuroblastomas (93.3\%) were GD2positive (26). Yeh et al. compared radioimmunoscintigraphy with an ${ }^{131}$ I-radiolabeled anti-GD2 $\mathrm{mAb}\left({ }^{131} \mathrm{I}-3 \mathrm{~F} 8\right),{ }^{131} \mathrm{I}-\mathrm{MIBG}$ (metaiodobenzylguanidine), and other imaging modalities in 42 consecutive patients with stage III or IV neuroblastoma (34). ${ }^{131}$ I-3F8 identified primary and metastatic neuroblastoma with excellent sensitivity and specificity. Surgical resection and subsequent histopathologic examination in nine patients revealed seven who were ${ }^{131} \mathrm{I}-3 \mathrm{~F} 8$ scan-positive and all tumors were confirmed as neuroblastoma; the two tumors that were ${ }^{131}$ I-3F8 negative were diagnosed as ganglioneuromas, one of which had microscopic foci of neuroblastoma. Zang et al., using immunohistology techniques, found $>50 \%$ GD2-positive cells in 5 of 5 frozen tissue specimens of human neuroblastoma (21). More recently, cytomorphologic examination with light microscopy plus multi-parametric flow cytometry with a panel that included disialoganglioside GD2 had greater sensitivity and specificity than cytomorphology alone for the detection of metastatic neuroblastoma in bone marrow (35).

\section{Small Cell Lung Cancer \\ Cell surface expression}

Gangliosides GM2 and GM1 are expressed by almost all subsets of lung cancer cell lines, whereas disialoganglioside GD2 is found characteristically in SCLC lines but is not expressed at all or is expressed at only very low levels by non-small cell lung cancer (NSCLC) lines (14). Disialoganglioside GD2 has been detected in cultured SCLC cell lines as well as in peripheral blood and bone marrow samples of patients with $\operatorname{SCLC}(14,36,37)$. Disialoganglioside GD2 expression is also much higher in SCLC cell lines than in normal lung cell lines $(25,36)$. However, quantitative data regarding expression of disialoganglioside GD2 by SCLC cells currently are limited.

Cheresh et al. detected disialoganglioside GD2 on both cultured cell lines and frozen biopsy specimens of human SCLC, using an ELISA assay and two anti-GD2 mAbs as molecular probes (36). Conversely, Zhang et al., using immunohistochemical analyses, identified $>50 \%$ GD2-positive cells in 0 of 6 frozen tissue specimens of human SCLC (21). Grant et al. evaluated the ability of an ${ }^{131}$ I-radiolabeled antiGD2 mAb to target tumor sites in 10 patients with untreated or recurrent/progressive SCLC (38). These radionuclide scans along with single photon emission tomography fusion image identified 
all known tumor sites except for a small brain metastasis in one patient. Yoshida et al. analyzed the expression of disialoganglioside GD2 across 44 lung cancer cell lines using flow cytometry and determined that GD2 was found characteristically in SCLC cell lines but was absent in or only minimally expressed by NSCLC lines, suggesting that GD2 may be a good therapeutic target in SCLC (14). Because disialoganglioside GD2 synthesis is dependent on GD2/GM2 synthase, Chen et al. conducted a pilot study of patients with SCLC and detected GD2/GM2 synthase in the peripheral blood of those with high expression in six SCLC cell lines (37). However, these results could not be confirmed in a prospective study by the authors, and they concluded that GD2/GM2 synthase is not a reliable biomarker for SCLC (37).

\section{Association between GD2 expression and malignant phenotypes}

Disialoganglioside GD2 promotes malignant phenotypes (20) such as increased proliferation, growth, migration, and invasion activity of SCLC tumor cells $(17,20)$, but the exact mechanisms underlying these effects are not well-known $(17,20)$. It has been speculated that GD2 may promote malignant phenotypes in SCLC by recruiting ASC amino-acid transporter (ASCT2)-a major glutamine transporter that has an essential role in tumor growth and progression-to lipid rafts (glycolipid-enriched domains on the outer leaflet of the plasma membrane bilayer), leading to enhanced glutamine uptake through ASCT2 $(12,20)$. In addition, overexpression and shedding of disialoganglioside GD2 by tumor cells into the tumor microenvironment can modulate normal cells present, supporting angiogenesis and tumor immune evasion (immunologic escape) while inhibiting cellular immune responses of lymphocytes (T-cell apoptosis, for example) and antigen-presenting cells $(7,39,40)$. In support of a critical role for disialoganglioside GD2 in cell proliferation, anti-GD2 mAbs (220-51 [mouse IgG3], KM666 [mouse IgG3], and KM1138 [mouse-human chimeric mAb]) suppressed the proliferation of GD2-expressing SCLC cells $(14,17)$ and induced apoptosis of SCLC cells via activation of caspases, a group of proteases with crucial roles in programmed cell death (17).

\section{Other Tumors}

Studies have shown that GD2 is expressed across a range of tumors. For example, Zhang et al. identified GD2-positive cells in 6 of 10 frozen tissue specimens $(60 \%)$ of human melanoma and 5 of 9 specimens (55.6\%) of sarcoma (21). Dobrenkov et al. found that the expression of disialoganglioside GD2 was highly prevalent $(\geq 70 \%)$ in pediatric melanoma and osteosarcoma, with uniformly strong intensity on immunohistochemistry staining in osteosarcoma, but did not exceed $50 \%$ in other pediatric solid tumors including rhabdomyosarcoma, Ewing sarcoma, and desmoplastic small round cell tumors (41). The authors concluded that disialoganglioside GD2 is a promising target for antibody-based therapy in pediatric solid tumors.

\section{Melanoma}

Disialoganglioside GD2 is the main ganglioside expressed on M21 melanoma cells (42). Cheresh et al. demonstrated with indirect immunofluorescence and scanning immunoelectron microscopy that disialoganglioside GD2 preferentially localizes into substrate-associated microprocesses originating from the plasma membrane of M21 melanoma cells and facilitates their attachment to fibronectin and other adhesive glycoproteins in the extracellular matrix $(42,43)$. Ohmi et al. compared the phenotypes of ganglioside-expressing melanoma cells and determined that disialoganglioside GD2 played a major role in increased cell growth, cell adhesion to collagen, and cell spreading, but did not play as large a role in cell migration velocity and invasion activity compared with gangliosides GD3, GM2, GM1, and GM3 (44). These results suggest that disialoganglioside GD2 may contribute to the fixation of melanoma cells at sites of metastasis. Cheresh and Pierschbacher found the relative surface expression of disialoganglioside GD2 antigens by 47 human melanoma cell lines varied from 80.5 to $100 \%$ depending on the anti-GD2 mAb and the analytic method used (43). Tsuchida et al. studied the ganglioside composition of melanoma tissue obtained by biopsy and identified disialoganglioside GD2 in $2.4 \%$ of 26 specimens obtained from skin and subcutaneous tissue, compared with $13.8 \%$ of 12 cultured melanomas derived from skin and subcutaneous tissue (45).

\section{Ewing sarcoma}

Ewing sarcoma has been studied for disialoganglioside GD2 expression, and the results ranged from no detectable surface expression to diffuse and/or intense staining in some tumors (46). More specifically, GD2 expression levels ranged from 40 to $90 \%$ from diagnostic biopsy samples of Ewing sarcoma (47). Kailayangiri et al. detected disialoganglioside GD2 expression by immunofluorescence staining in 10 of 10 Ewing sarcoma cell lines and 3 of 3 primary cell cultures, concluding that surface expression of disialoganglioside GD2 is a characteristic of Ewing sarcoma and that GD2 provides an appropriate target antigen for therapeutic strategies to eradicate micrometastases and reduce the risk of recurrence in patients with high-risk disease (48). Accordingly, disialoganglioside GD2 is a potential therapeutic target in Ewing sarcoma.

\section{Osteosarcoma}

Roth et al. used immunohistochemistry analysis to study the expression of disialoganglioside GD2 in 44 patient-derived osteosarcoma cell lines and observed higher staining intensity in specimens obtained at tumor recurrence compared with specimens obtained at initial resection (49). This finding suggests that disialoganglioside GD2 plays a role in chemotherapy resistance and/or tumor progression of osteosarcoma. Zhu et al. identified a synergistic effect of an anti-GD2 mAb and cisplatin compared with their individual effects on osteosarcoma cells; the results suggested that cisplatin plus an anti-GD2 mAb could be an effective therapeutic strategy for osteosarcoma (50). Heiner et al. tested fresh-frozen samples of osteosarcoma from 17 patients for the presence of GD2 by immunofluorescence following exposure to anti-GD2 $\mathrm{mAb}$ and found that 15 of 17 tumors (88.2\%) showed strong reactivity and high intensity of $3+$ or $4+$ in more than 95\% cells stained; the two tumors with weak intensity of staining proved to be variants of malignant fibrous histiocytoma (51). 
Butch et al. used positron emission tomography (PET) to evaluate the ability of a novel radiolabeled, humanized anti-GD2 $\mathrm{mAb}$ $\left(\left[{ }^{64} \mathrm{Cu}\right] \mathrm{Cu}-\mathrm{Bn}-\mathrm{NOTA}-\mathrm{hu} 14.18 \mathrm{~K} 322 \mathrm{~A}\right)$ to detect GD2 expression in a mouse model of osteosarcoma in vivo (52). Tumor uptake of the radiolabeled $\mathrm{mAb}$ was 7 -fold higher in modestly GD2expressing osteosarcomas than in a GD2-negative tumor, and PET scan could identify lesions as small as $29 \mathrm{~mm}^{3}$ in a $34 \%$ GD2positive model of metastatic osteosarcoma of the lung. These results support the utility of disialoganglioside GD2 imaging with PET to measure GD2 expression in osteosarcoma and thus maximize the clinical impact of anti-GD2 targeted therapy.

\section{Soft tissue sarcoma}

Chang et al. studied tissue from 56 freshly frozen human sarcomas by immunohistochemical staining and found that 52 (93\%) expressed disialoganglioside GD2 (53). The intensity of GD2 expression varied among sarcoma types and was weakest for more aggressive tumors (embryonal rhabdomyosarcoma and synovial sarcoma). Supporting this observation, Saraf et al. identified disialoganglioside GD2 expression in only $25 \%$ of 16 pediatric rhabdomyosarcoma samples (54).

\section{Glioma}

Disialoganglioside GD2 is expressed by some gliomas $(25,55)$ including glioblastomas (56), and GD2 expression by these tumors is associated with increased cell growth, mobility, and invasiveness (57). Longee et al. used an anti-GD2 mAb and identified disialoganglioside GD2 expression in $80 \%$ of malignant glioma cell lines $(N=20)$ and tumor biopsies of malignant glioma $(N=30)(55)$.

\section{Retinoblastoma}

Disialoganglioside GD2 is expressed on the cell surface of retinoblastomas and may be detectable in the serum (58), bone marrow (59), and cerebrospinal fluid (60) of patients with extraocular dissemination. Chantada et al. identified bone marrow invasion by retinoblastoma in 11 of 27 patients with extraocular disease (59). Disialoganglioside GD2 was expressed intensely in the bone marrow of all nine patients whose marrow specimens were examined immunocytologically. Sujjitjoon et al. immunohistochemically examined surgical specimens from eight patients with retinoblastoma and found all to be strongly positive for disialoganglioside GD2 expression (61). Andersch et al. studied the expression of disialoganglioside GD2 in 11 retinoblastoma cell lines and found GD2 to be expressed by all (62).

\section{Breast and bladder cancer}

Disialoganglioside GD2 is also expressed by a small number of tumors not of neuroectodermal origin. For example, GD2 has been identified as a marker for breast cancer stem cells in a small proportion of human breast cancer cell lines (9). Orsi et al. found that breast cancer cells obtained by surgical resection of tumor from 63 previously untreated patients were positive for disialoganglioside GD2 in 37 cases (59\%); the percentage of cells that stained positive for GD2 by immunohistochemistry in these specimens ranged between 3 and $100 \%$ (mean: 52\%) (63). In addition, the majority of aggressive breast cancer subtypes (triple-negative and metaplastic specimens) tested positive for disialoganglioside GD2. Mansoori et al. showed higher GD2 expression in breast cancer samples from patients with advanced histological grade $(P=0.02)$, lymph node invasion $(P=0.04)$, larger tumor size $(P=0.04)$, and older age $(P=0.04)$ (64). Finally, Vantaku et al. reported that high-grade bladder cancer tissue and cell lines express disialoganglioside GD2 at a level higher than that of low-grade bladder cancer, and GD2-expressing muscle-invasive bladder cancer cells proliferated more rapidly than GD2-negative cells (65). The authors considered disialoganglioside GD2 expression to be a biomarker for aggressive bladder cancer.

\section{TARGETING DISIALOGANGLIOSIDE GD2-EXPRESSING TUMORS}

In addition to neuroblastoma, anti-GD2 targeted therapy currently is being investigated as treatment of a number of GD2expressing tumors including SCLC in adults, osteosarcoma in children and adults, glioma, soft tissue sarcoma, Ewing sarcoma, retinoblastoma, and melanoma.

\section{Anti-GD2 mAbs}

\section{Proposed Mechanisms of Action in Cancer}

Anti-GD2 mAbs have three proposed mechanisms of action (MOA) against disialoganglioside GD2-expressing tumor cells: (1) induction of phagocytosis by macrophages and destruction of tumor cells by natural killer (NK) cells and granulocytes via antibody-dependent cell-mediated cytotoxicity (ADCC), (2) lysis of tumor cells via complement-dependent cytotoxicity (CDC), and (3) direct induction of cell death due to specific binding of anti-GD2 mAbs to GD2 (Figure 2) (66-68). In ADCC-the primary MOA-tumor-bound anti-GD2 mAbs engage $\mathrm{Fc} \gamma$ receptors on the surface of NK cells and granulocytes, followed by the release from these cells of cytotoxic granules (serine proteases, or granzymes [specifically, granzyme B]) and cytokines (particularly perforin, a glycoprotein that creates pores in targeted cell membranes) (69), causing Fc-dependent phagocytosis and lysis of tumor cells $(68,70)$. CDC is induced through binding of the serine protease complex $\mathrm{C} 1$ to the $\mathrm{FC}$ domains of two or more mAbs binding to antigens expressed on tumor cells (70). This classic complement pathway results in an activation cascade causing the membrane attack complex (MAC) to disrupt the target cell. In mAb-mediated CDC, it is hypothesized that antibody-coated tumor cells activate the complement system, which is followed by cancer cell lysis via MAC accumulation or phagocytosis of opsonized cancer cells by macrophages and granulocytes.

Anti-GD2 mAbs also may induce cell death directly without involving immune mechanisms, combining features of apoptosis and necrosis in GD2-positive tumor cell lines but not in GD2-negative tumors $(67,71)$. Direct induction of mAbmediated tumor cell death occurs in a dose-dependent manner, with the strongest cytotoxic effects observed in tumor cells with the highest expression of GD2. The process appears to involve alteration of mitochondrial membrane potential, 


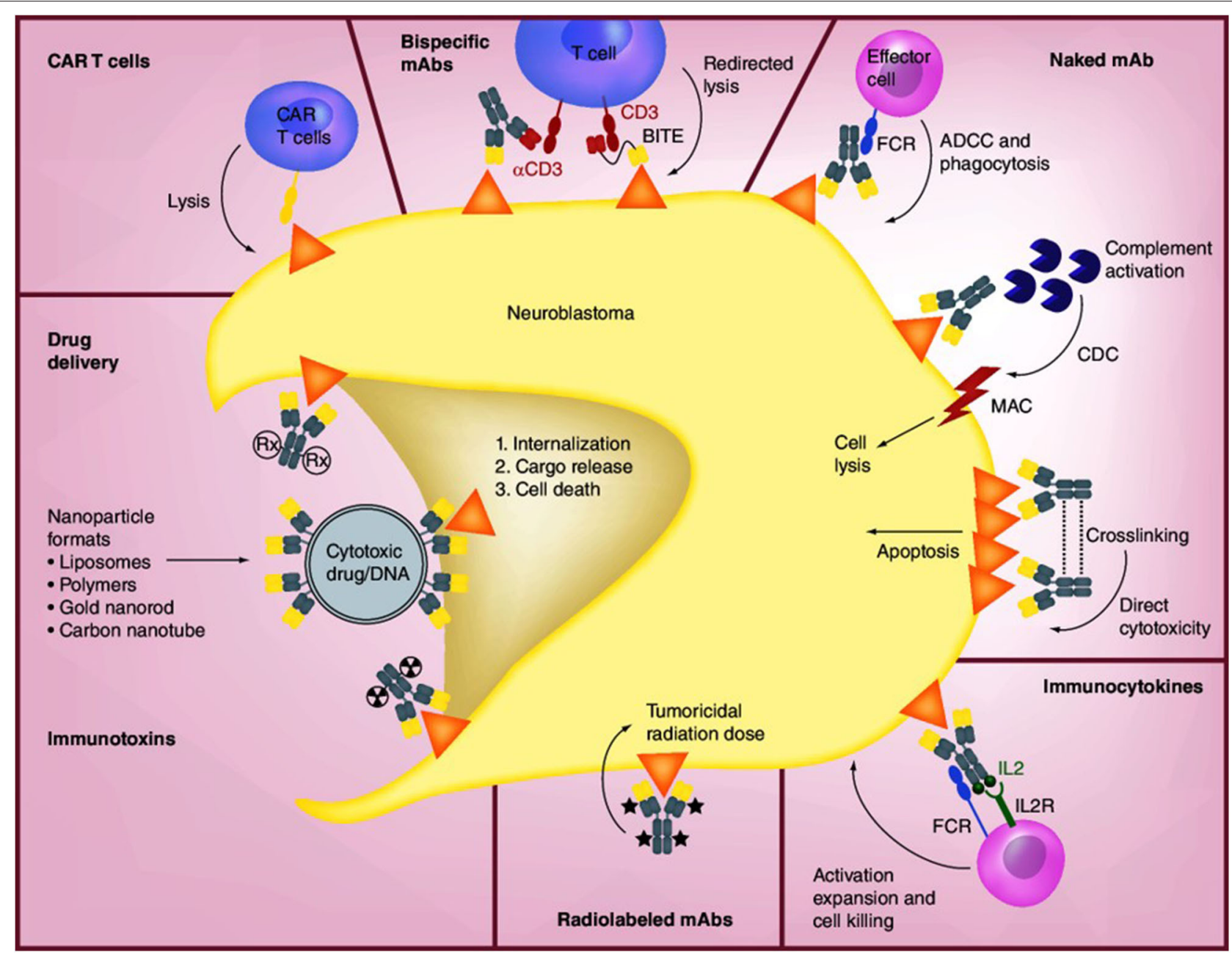

FIGURE 2 | Mechanisms of anti-GD2 mAbs and other therapeutic approaches [Source: Perez Horta et al. (66)]. The binding of anti-GD2 mAbs to GD2 on the surface of neuroblastoma cells results in three proposed antitumor effects: (1) attraction of NK cells, granulocytes, and other FCR-expressing effector cells to promote ADCC, together with the recruitment of macrophages and monocytes to mediate phagocytosis; (2) induction of CDC by binding of the mAb to complement component 1q (C1a), followed by activation of the complement cascade and transport of MAC to the plasma membrane of the tumor cell; and (3) direct cytotoxicity through the initiation of apoptosis. The concentration of IL-2-based immunocytokines at the tumor promotes activation of tumoricidal effector cells via their IL-2R and FC receptors. Radiolabeled mAbs serve the dual function of tumor radioimmunodetection and delivery of tumoricidal doses of radiation to tumor cells. Immunotoxins and drug conjugates can deliver various toxic agents to tumor cells, followed by internalization and release of the toxic agent and cell death. CAR-T cells are engineered ex vivo to recognize the tumor antigen and promote tumor cell lysis. Bispecific mAbs are available in a variety of forms such as hybrid bifunctional mAbs with two different antigen-specific regions or as BITE with the primary objective of redirecting T cells for tumor lysis by engaging tumor antigen and costimulatory molecules such as CD3. ADCC, antibody-dependent cell-mediated cytotoxicity; BITE, bispecific T-cell engagers; CAR, chimeric antigen receptor; CDC, complement-dependent cytotoxicity; FCR, FC-receptor; IL2, interleukin-2; IL2R, interleukin-2 receptor; mAb, monoclonal antibody; MAC, membrane attack complex. Reproduced with permission as agreed by Future Medicine Ltd.

change in plasma membrane permeability, and induction of apoptotic volume decrease (apoptotic whole-cell shrinkage, a major hallmark of apoptotic cell death). In addition, antiGD2 mAbs inhibit attachment of circulating malignant cells to protein components of the extracellular matrix (43), potentially representing a fourth MOA.

\section{Clinical Availability and Selection}

Therapeutic mAbs against disialoganglioside GD2 can be generated using murine, chimeric, humanized, and human antibody constructs $(72,73)$. Development of anti-ganglioside agents generally and anti-GD2 agents specifically requires engineering GD2 mAbs. The major pharmacologic obstacles to successful treatment of GD2-expressing tumors with anti-GD2 mAbs include insufficient antibody affinity to mediate ADCC, inadequate penetration of antibody into the microenvironment of the tumor, and toxicity related to disialoganglioside GD2 expression by normal tissues (particularly peripheral nerves) (74). The murine IgG3 monoclonal antibody $3 \mathrm{~F} 8$ was developed in 1985 and was the first specific anti-GD2 antibody (32), followed by the murine $\operatorname{IgG} 3 \mathrm{mAb} 14.18$ and then the chimeric IgG1 murine-human mAb ch14.18 (75). Chimeric and 
humanized anti-GD2 mAbs are less immunogenic, exhibit longer half-lives, and more efficiently promote effector functions than murine mAbs $(73,76)$.

Preclinical pharmacologic studies characterized the binding and activity profiles of ch14.18 and 14.G2a, a murine anti-GD2 $\mathrm{mAb}$. Mujoo et al. and Mueller et al. reported that both of these antibodies had similar binding affinity for disialoganglioside GD2 and demonstrated the ability to mediate ADCC and CDC (77, 78). Mujoo et al. demonstrated highly specific and avid binding of ch14.18 to disialoganglioside GD2 expressed by a variety of tumor cell lines of neuroectodermal origin, including eight different neuroblastoma cell lines and several melanoma, glioblastoma, and SCLC lines (25). Earlier work had suggested a functional role for disialoganglioside GD2 in helping to facilitate the attachment of neuroblastoma and melanoma cells to the extracellular matrix $(42,43)$. For example, Mueller et al. reported that the number of GD2 binding sites on cell lines correlated with levels of antibody binding (78). These findings made anti-GD2 antibodies appealing candidates for further evaluation.

\section{Dinutuximab}

Dinutuximab (ch14.18; Unituxin ${ }^{\circledR}$, United Therapeutics Corporation) is produced in mouse myeloma cell line SP2/0 (75). Dinutuximab used together with granulocyte-macrophage colony-stimulating factor (GM-CSF), interleukin-2 (IL-2), and isotretinoin was licensed in March 2015 by the U.S. Food and Drug Administration (FDA) "for the treatment of pediatric patients with high-risk neuroblastoma who achieve at least a partial response to prior first-line, multi-agent, multimodality therapy" (79). Dinutuximab is the first FDA-approved treatment specifically for high-risk neuroblastoma. Dinutuximab was also approved in the EU in August 2015 for the same indication.

\section{Dinutuximab beta}

Dinutuximab beta (ch14.18.CHO; Qarziba ${ }^{\circledR}$, EUSA Pharma), is a murine-human chimeric anti-GD2 $\mathrm{mAb}$ produced in Chinese hamster ovary $(\mathrm{CHO})$ cells (75). $\mathrm{CHO}$ cells for mAb expression provide a glycosylation pattern that includes only small amounts of the sialic acid $\mathrm{N}$-glycolylneuraminic acid, avoiding its rapid clearance by human autoantibodies, and precludes the potential murine virus contamination associated with SP2/0 cells (68). Dinutuximab beta was approved by the European Commission in May 2017 "for the treatment of high-risk neuroblastoma in patients aged 12 months and above who have previously received induction chemotherapy and achieved at least a partial response followed by myeloablative therapy and stem cell transplantation." It is also approved in the EU for patients "with a history of relapsed or refractory neuroblastoma with or without residual disease." Dinutuximab beta currently is investigational in the US and is being evaluated with IL-2 and isotretinoin for treatment of neuroblastoma (80). In the pivotal phase III trial, however, the investigators noted that there was "no evidence that addition of subcutaneous IL-2 to immunotherapy with dinutuximab beta...improved outcomes in patients with high-risk neuroblastoma" but IL-2 "was associated with greater toxicity than dinutuximab beta alone" (81).
TABLE 1 | ch14.18, ch14.18CHO, and Investigational anti-GD2 mAbs* .

\begin{tabular}{|c|c|c|}
\hline Antibody & Description & Features \\
\hline \multicolumn{3}{|l|}{ Approved } \\
\hline $\begin{array}{l}\text { ch14.18 } \\
\text { (dinutuximab) }\end{array}$ & $\begin{array}{l}\text { Chimeric (murine-human) } \\
\text { lgG1 mAb produced in } \\
\text { murine myeloma SP2 } / 0 \text { cell } \\
\text { line }\end{array}$ & $\begin{array}{l}\text { FDA- and EMA-approved } \\
\text { for neuroblastoma }{ }^{\dagger}\end{array}$ \\
\hline $\begin{array}{l}\text { ch14.18/CHO } \\
\text { (dinutuximab } \\
\text { beta) }\end{array}$ & $\begin{array}{l}\text { Chimeric (murine-human) } \\
\text { lgG1 mAb produced in } \mathrm{CHO} \\
\text { cells }\end{array}$ & $\begin{array}{l}\text { EMA-approved for } \\
\text { neuroblastoma }{ }^{\ddagger}\end{array}$ \\
\hline \multicolumn{3}{|l|}{ Investigational } \\
\hline 14.18 & Murine lgG1 mAb & Lower ADCC than 14.G2a \\
\hline 14.G2a & Murine lgG2a mAb & Used to generate ch14.18 \\
\hline 3F8 & Murine lgG3 mAb & $\begin{array}{l}\text { Large experience as single } \\
\text { agent and in combinations }\end{array}$ \\
\hline Hu3F8 & Humanized 3F8 mAb & $\begin{array}{l}\text { Less complement activation } \\
\text { than } 3 \text { F8 }\end{array}$ \\
\hline${ }^{131} \mid-3 F 8$ & $\begin{array}{l}\text { Murine mAb fused with } \\
\text { iodine } 131\end{array}$ & $\begin{array}{l}\text { Radioimmunoconjugate } \\
\text { with radioimaging and } \\
\text { radioimmunotherapeutic } \\
\text { properties }\end{array}$ \\
\hline Hu14.18-IL-2 & $\begin{array}{l}\text { Humanized } 14.18 \mathrm{mAb} \\
\text { fused with IL-2 }\end{array}$ & $\begin{array}{l}\text { Clinical trials of fusion } \\
\text { version with IL-2 }\end{array}$ \\
\hline Hu14.18K322A & $\begin{array}{l}\text { Point mutation in hu14.18 } \\
\text { (biologically modified from } \\
\text { 14.G2a) }\end{array}$ & $\begin{array}{l}\text { Designed to reduce } \\
\text { complement activation and } \\
\text { subsequent painful side } \\
\text { effects }\end{array}$ \\
\hline ME36.1 & $\begin{array}{l}\text { Murine mAb class switched } \\
\text { to } \lg G 1 \text { and } \lg G 2 a\end{array}$ & Cross reacts with GD3 \\
\hline $8 B 6$ & $\begin{array}{l}\text { mAb that binds to } \\
\text { O-acetyl-GD2 antigen }\end{array}$ & $\begin{array}{l}\text { May reduce painful side } \\
\text { effects }\end{array}$ \\
\hline L72 & Fully human IgM mAb & $\begin{array}{l}\text { Produced by } \\
\text { EBV-transformed cell lines }\end{array}$ \\
\hline
\end{tabular}

ADCC, antibody-dependent cellular cytotoxicity; CHO, Chinese hamster ovary; EBV, Epstein-Barr virus; EMA, European Medicines Agency; FDA, U.S. Food and Drug Administration; mAb, monoclonal antibody.

${ }^{*}$ Adapted from Keyel (75).

${ }^{\dagger}$ Indicated, in combination with granulocyte-macrophage colony-stimulating factor (GM-CSF), interleukin-2 (IL-2), and 13-cis-retinoic acid (RA), for the treatment of pediatric patients with high-risk neuroblastoma who achieve at least a partial response to prior first-line multiagent, multimodality therapy.

¥ Indicated for the treatment of high-risk neuroblastoma in patients aged 12 months and above, who have previously received induction chemotherapy and achieved at least a partial response, followed by myeloablative therapy and stem cell transplantation, as well as patients with history of relapsed or refractory neuroblastoma, with or without residual disease. Prior to the treatment of relapsed neuroblastoma, any actively progressing disease should be stabilized by other suitable measures. In patients with a history of relapsed/refractory disease and in patients who have not achieved a complete response after first line therapy, Qarziba should be combined with interleukin-2 (IL-2).

\section{Investigational anti-GD2 mAbs}

A number of investigational anti-GD2 mAbs currently are being evaluated in clinical trials, primarily for neuroblastoma, and these mAbs are summarized in Table 1. For example, humanized 3F8 (3F8 humanized; hu3F8; naxitamab) $\mathrm{mAb}$ has higher affinity than dinutuximab for disialoganglioside GD2 antigen and superior ADCC (but not CDC) than murine 3F8 mAb (82). Humanized anti-GD2 antibodies have been developed to diminish the potential for patients to generate human anti-murine antibodies, which might block the antitumor activity of anti-GD2 antibodies (75). In a phase I clinical trial in patients with resistant 
or recurrent neuroblastoma, hu3F8 had low immunogenicity, produced modest toxic effects, and possessed considerable activity against neuroblastoma. In addition, multimerization and pegylation of single-chain fragment variables $(\mathrm{scFv})$ of antiGD2 antibodies were shown to significantly increase circulation time compared with that of monomeric scFv in the blood and to increase tumor penetration of the anti-GD2 antibodies in a syngeneic GD2-positive mouse cancer model (83). Furman et al. reported the results of a non-randomized phase II trial in which the humanized disialoganglioside GD2 mAb hu14.18K322A was coadministered with six courses of induction chemotherapy in 42 children with newly diagnosed high-risk neuroblastoma (84) Thirty two patients (76.2\%) experienced at least a partial response following two courses of chemoimmunotherapy, together with a median reduction of volume of the primary tumor of $76 \%$. The authors concluded that "Adding hu14.18K322A to induction chemotherapy produced early partial response or better in most patients, reduced tumor volumes, improved cancer-specific survival at the end of induction, and yielded an encouraging 2-year event-free survival."

The severe nociceptive pain that commonly accompanies treatment with anti-GD2 mAbs may limit the dose that can be infused and, as a result, potentially reduce clinical efficacy against GD2-expressing tumors such as neuroblastoma $(1,11)$. Anti-Oacetylated GD2 mAbs are specific for the $O$-acetylated derivative of GD2, which also is expressed by GD2-positive tumors but, unlike GD2, not by peripheral nerve fibers. Anti-O-acetylated GD2 mAbs maintain ADCC activity against GD2-expressing tumors but limit complement activation and, accordingly, decrease neurotoxic side effects. One of these anti- $O$-acetylated GD2 mAbs, mAb 8B6, is able to inhibit the growth of GD2expressing tumor cells with anti-tumor activity comparable to that of anti-GD2 mAbs.

\section{Current Research and Clinical Utility}

Table 2 summarizes currently ongoing studies of anti-GD2 mAbs in solid tumors listed in ClinicalTrials.gov.

\section{Neuroblastoma}

Targeted therapy with anti-GD2 mAbs has transformed the management of neuroblastoma. Cheung et al. reported the results of the first study of an anti-GD2 mAb (3F8) in eight patients with this tumor; two achieved a complete response, another two achieved stable disease, and four experienced progressive disease as best outcome (32). It was later observed that the response to treatment in patients with neuroblastoma was improved when GM-CSF, IL-2, and the biologic disease modifier isotretinoin (13cis-retinoic acid, a retinoid derivative of vitamin A) are combined with anti-GD2 mAbs $(73,85,86)$ to enhance ADCC (68). GMCSF may enhance anti-tumor effects through direct activation and increased numbers of macrophages and granulocytes, and IL-2 is believed to activate NK cells, generating lymphokineactivated NK cells that augment ADCC (87). However, the results of a recent study failed to show evidence that the concurrent administration of IL-2 and the anti-GD2 mAb dinutuximab beta "improved outcomes in high-risk neuroblastoma patients who had responded to standard induction and consolidation
TABLE 2 | Currently ongoing clinical trials of anti-GD2 mAbs.

Tumor(s) Study description and status

ch14.18 (dinutuximab)

Neuroblastoma Phase I study of ${ }^{131}$ I-MIBG + dinutuximab to determine a recommended phase II pediatric dose; currently recruiting; last updated September 2018 (NCT03332667)

Neuroblastoma Phase II study to evaluate dinutuximab + cytokines (GM-CSF and IL-2) in high-risk patients; active, not recruiting; last updated July 2018 (NCT02169609)

Neuroblastoma Phase I study of lenalidomide + dinutuximab \pm isotretinoin for relapsed/refractory neuroblastoma; active, not recruiting; last updated October 2019 (NCT01711554)

Neuroblastoma Phase I study to determine the maximum tolerated dose of expanded NK cells + dinutuximab in relapsed/recurrent neuroblastoma; recruiting; last updated May 2019 (NCT02573896)

Neuroblastoma Phase II study of irinotecan + temozolomide + dinutuximab \pm eflornithine in relapsed/refractory neuroblastoma; recruiting; last updated September 2019 (NCT 03794349)

Neuroblastoma Phase II study of dinutuximab + sargramostim + combination chemotherapy in newly diagnosed high-risk neuroblastoma undergoing stem cell transplant; recruiting; last updated October 2019 (NCT03786783)

Osteosarcoma Phase II study of dinutuximab + sargramostim in recurrent osteosarcoma; active, not recruiting; last updated October 2019 (NCT02484443)

hu14.18K322A

Neuroblastoma Phase II study of therapy for children with advanced stage neuroblastoma; last updated October 2019 (NCT01857934)

Neuroblastoma, Observational study of pretreatment anti-therapeutic osteosarcoma, antibodies (anti-hu14.18K322A antibodies as detected by the melanoma, Ewing human anti-human antibodies [HAHA] test); last updated family of tumors January 2020 (NCT02159443)

hu3F8

Neuroblastoma Phase I study of humanized anti-GD2 antibody hu3F8 and allogeneic natural killer cells for high-risk neuroblastoma; last updated October 2019 (NCT02650648)

Neuroblastoma Phase II study of naxitamab (hu3F8) for high-risk neuroblastoma patients with primary refractory disease or incomplete response to salvage treatment in bone and/or bone marrow; last updated January 2020 (NCT03363373)

Neuroblastoma Phase I/II study of combination therapy of antibody hu3F8 with GM-CSF in patients with relapsed/refractory high-risk neuroblastoma; last updated November 2019 (NCT01757626)

Neuroblastoma Phase II study of monoclonal antibody 3F8 and sargramostim in treating patients with neuroblastoma; last updated October 2019 (NCT00072358)

Osteosarcoma Phase II study of humanized monoclonal antibody 3F8 (hu3F8) with GM-CSF in the treatment of recurrent osteosarcoma; last updated January 2020 (NCT02522786)

\section{F8}

Neuroblastoma Phase I study of beta-glucan and monoclonanal antibody 3F8 in treating patients with metastatic neuroblastoma; last updated February 2019 (NCT00492167)

Neuroblastoma Phase 2 study of ${ }^{131} \mathrm{I}-\mathrm{mAb} 3 \mathrm{~F} 8$ in treating patients with central nervous system cancer or leptomeningeal cancer; last updated October 2019 (NCT00445965) 
TABLE 2 | Continued

\begin{tabular}{|c|c|}
\hline Tumor(s) & Study description and status \\
\hline \multicolumn{2}{|c|}{ ch14.18/CHO (dinutuximab beta) } \\
\hline Neuroblastoma & $\begin{array}{l}\text { Phase I study of investigational medicinal products in children } \\
\text { with relapsed/refractory neuroblastoma; last updated July } \\
2019 \text { (NCT02914405) }\end{array}$ \\
\hline Neuroblastoma & $\begin{array}{l}\text { Phase III study of high-risk neuroblastoma } 1.8 \text { of } \\
\text { SIOP-Europe (SIOPEN); last updated June } 2018 \\
\text { (NCT01704716) }\end{array}$ \\
\hline
\end{tabular}

GM-CSF, granulocyte-macrophage colony-stimulating factor; IL-2, interleukin-2; $m A b$, monoclonal antibody; MIBG, metaiodobenzylguanidine; NK, natural killer.

treatment" (81). In addition, "IL-2 with dinutuximab beta was associated with greater toxicity than dinutuximab beta alone." It also should be noted that a clinical study comparing antiGD2 mAb alone with anti-GD2 mAb plus GM-CSF has not been conducted. A study by Agarwal et al. found G-CSF to be a "tumorigenic growth factor for neuroblastoma" by promoting the expansion of cancer stem cell-like subpopulations in vitro and in vivo, and the authors suggested "a comprehensive re-evaluation of the clinical use of G-CSF in these patients" (88).

Zhang et al. determined that either anti-GD2 mAb or cytokine-induced killer (CIK)/NK cells isolated from cord blood mononuclear cells significantly provoked apoptosis of neuroblastoma cell line SK-N-SH compared with controls, as assessed by flow cytometry (89). The authors also showed that anti-GD2 $\mathrm{mAb}$ and CIK/NK cells in combination significantly increased apoptosis compared with either treatment separately in vitro. A currently ongoing clinical trial (ClinicalTrials.gov Identifier NCT02573896) is testing ex vivo-expanded NK cells combined with dinutuximab for treatment of children with refractory or recurrent neuroblastoma, based on in vivo (mouse model) data published by Liu et al. in 2013 (90).

Disialoganglioside can serve as a prognostic marker as well as a biomarker for neuroblastoma. Balis et al. found that disialoganglioside GD2 was not elevated in children with 10 other childhood cancers except for medulloblastoma (median: $34 \mathrm{nM}$; range: 6-111 nM) (29). The authors then measured disialoganglioside GD2 in pretreatment serum or plasma samples from 128 children with neuroblastic tumors (ganglioneuroma, ganglioneuroblastoma, and neuroblastoma, 73 of which were high-risk), 8-12 each with 10 other common childhood cancers, and 40 without cancer (controls) (91). The median concentration of GD2 in children with high-risk neuroblastoma was $167 \mathrm{nM}$ (range: 16.1-1,060 nM), which was 30-fold higher than the median concentration $(5.6 \mathrm{nM})$ in controls $(P<0.00001)$. Notably, disialoganglioside GD2 was not elevated in serum from children with differentiated neuroblastic tumors or with other childhood cancers. The authors concluded that disialoganglioside GD2 may be a sensitive and specific circulating biomarker for high-risk neuroblastoma.

Terzic et al. analyzed the expression of disialoganglioside GD2 using immunohistochemical staining prior to targeted therapy with anti-GD2 mAb ch14.18 in 152 tumor samples from patients with neuroblastomas (92). GD2 was expressed in $96 \%$ of samples, although the percentage of GD2-positive tumor cells varied across samples. There was an association between a low proportion of GD2-positive cells prior to immunotherapy with ch14.18 and relapse, and the sensitivity of neuroblastoma cell lines to NK cell-mediated lysis varied with the proportion of GD2-positive cells. The results suggested that the proportion of neuroblastoma cells expressing disialoganglioside GD2 in the presence of ch14.18 might be predictive of efficacy.

The U.S. National Cancer Institute was primarily responsible for the development of ch14.18 and sponsored the initial clinical studies over a 20-year period (93-96). This culminated in the pivotal phase III ANBL0032 trial conducted by the Children's Oncology Group (COG) (86). The study included 226 pediatric patients at a median age of 3.8 years (range: 11 months -15 years) with high-risk neuroblastoma who had completed induction therapy, autologous hematopoietic stem cell transplantation (HSCT), and radiotherapy and had achieved at least a partial response before HSCT. Patients were randomized 1:1 to receive up to five cycles of dinutuximab in combination with GM-CSF, IL-2, and isotretinoin followed by a single cycle of isotretinoin alone in the experimental arm or up to 6 months of isotretinoin alone in the control arm. The primary endpoint was eventfree survival, defined as the time from randomization to first relapse, progressive disease, secondary malignancy, or death. At interim analysis, there was improvement in event-free survival in patients treated with dinutuximab combination therapy [hazard ratio (HR): 0.57 ; 95\% confidence interval (CI): $0.37-$ $0.89 ; P=0.01$ ]. Overall survival at 2 years also demonstrated an improvement for patients treated with dinutuximab (HR: 0.58; 95\% CI: 0.37-0.91). At the time of the interim report, median overall survival had not been reached in either arm. An updated survival analysis with a median follow-up of 10.3 years (range: $2.3-10.7$ ) found that $73 \%$ of patients treated with the dinutuximab combination were still alive compared with $58 \%$ of patients treated with isotretinoin alone. Based on these interim results, the COG Data Monitoring Committee recommended terminating randomization, and patients who were previously randomized to receive isotretinoin alone were allowed to cross over to dinutuximab. Notable common adverse events $(\geq 25 \%)$ in patients enrolled in the dinutuximab arm of the trial included increased alanine aminotransferase and aspartate aminotransferase, anemia, capillary leak syndrome, diarrhea, infusion reactions, neutropenia, thrombocytopenia, pyrexia, and vomiting. Dinutuximab also caused severe neuropathic pain, and treatment with intravenous opioids was necessary before, during, and after dinutuximab infusion. Morphine administered by nurse- or patient-controlled analgesia is effective for managing the transient nociceptive, generalized pain accompanying dinutuximab therapy (97).

The randomized phase II ANBL1221 trial conducted by the COG compared the combination of irinotecan, temozolomide, and temsirolimumus with irinotecan, temozolomide, and dinutuximab plus GM-CSF in children with relapsed or refractory neuroblastoma (98). The primary endpoint was "best overall response based on results of CT/MRI imaging, MIBG scans and bone marrow aspirates/biopsies, determined after completion of six cycles of protocol therapy." The authors stated that "irinotecan-temozolomide-dinutuximab 
met protocol-defined criteria for selection as the combination meriting further study whereas irinotecan-temozolomidetemsirolimus did not. Irinotecan-temozolomide-dinutuximab shows notable anti-tumor activity in patients with relapsed or refractory neuroblastoma."

Mechanisms of resistance to anti-GD2 mAbs have not been characterized adequately (75), and the reasons for treatment failure have not been identified (99). However, the relatively low response rate observed in the pivotal ANBL0032 phase III trial could be associated with "immune escape mechanisms" utilized by neuroblastoma, including the incursion of immunosuppressive cells, production of abnormal constituents of antigen processing machinery, elaboration of local immunosuppressive factors, and modification of cancer cell metabolism (100). Progression of neuroblastoma during or following treatment with anti-GD2 mAbs also may result from insufficient tumor cell exposure to the antibody, a response by immune effector cells that is inadequate to induce ADCC or CDC, or inherent resistance of the patient's neuroblastoma cell line to antibody therapy (75). Nevertheless, a Cochrane Database Systematic Review published in April 2019 concluded that, based on the results of the pivotal phase III ANBL0032 trial, the evidence base favors "dinutuximab-containing immunotherapy compared to standard therapy concerning overall survival and event-free survival in people with high-risk neuroblastoma pre-treated with autologous HSCT" (101).

\section{Small cell lung cancer}

Cheresh et al. demonstrated the presence of disialoganglioside GD2 on SCLC-derived tissue and established that the addition of anti-GD2 mAb 14.18 lysed SCLC tumor cells (36). Subsequently, Yoshida et al. showed that addition of anti-GD2 mAbs to cultures of SCLC cells expressing high levels of GD2 and GD3 resulted in marked suppression of growth of GD2-expressing cells and enhanced the apoptotic effect of anti-cancer drugs against SCLC (17). Aixinjueluo et al. suggested that apoptosis of SCLC cells induced by anti-GD2 mAbs may result from the dephosphorylation of focal adhesion kinase, a cytoplasmic tyrosine kinase with anti-apoptotic activity (102).

The DISTINCT study is a recently completed clinical trial of an anti-GD2 mAb in SCLC (ClinicalTrials.gov Identifier NCT03098030). It is a two-part open-label, randomized, unblinded, parallel assignment phase II/III study comparing second-line dinutuximab and irinotecan with irinotecan alone in patients with relapsed or refractory SCLC who progressed following first-line platinum-based therapy (103). In Part 1 of the study, the dose-escalation phase, 12 patients were treated with intravenous dinutuximab in combination with irinotecan $\left(350 \mathrm{mg} / \mathrm{m}^{2}\right)$ on Day 1 of 21 -day cycles. The combination of dinutuximab and irinotecan was well-tolerated at a median dinutuximab dose of 14 (range: $10-16) \mathrm{mg} / \mathrm{m}^{2}$, with no unanticipated adverse events (AEs). AEs of pain were predominantly Grade 1 and did not result in dinutuximab dose reductions, discontinuations, or hospitalizations. Topline results from part 2 of the study, which was designed to determine whether the combination of dinutuximab and irinotecan prolongs overall survival compared with irinotecan alone, did not meet its primary efficacy objective (104).

\section{Osteosarcoma}

Butch et al. used positron emission tomography (PET) to evaluate the ability of a novel radiolabeled, humanized anti-GD2 mAb $\left(\left[{ }^{64} \mathrm{Cu}\right] \mathrm{Cu}-\mathrm{Bn}-\mathrm{NOTA}-\mathrm{hu} 14.18 \mathrm{~K} 322 \mathrm{~A}\right)$ to detect GD2 expression in a mouse model of osteosarcoma in vivo (52). Tumor uptake of the radiolabeled $\mathrm{mAb}$ was 7 -fold higher in modestly GD2expressing osteosarcomas than in a GD2-negative tumor, and PET scan could identify lesions as small as $29 \mathrm{~mm}^{3}$ in a $34 \%$ GD2positive model of metastatic osteosarcoma of the lung. These results support the utility of disialoganglioside GD2 imaging with PET to measure GD2 expression in osteosarcoma and thus maximize the clinical impact of anti-GD2 targeted therapy.

There are currently eight ongoing studies of anti-GD2 targeted therapy in osteosarcoma listed in ClinicalTrials.gov.

\section{Soft tissue sarcoma}

Previous studies of hu14.18 mAb-IL2 fusion protein and of ${ }^{131} \mathrm{I}-$ 3F8 mAb were open to various tumor types including sarcoma and completed in 2005, but no results are publicly available and studies no longer are being conducted.

\section{Melanoma}

Tsao et al. showed that anti-GD2 mAb 3F8 induces apoptosis of GD2-expressing melanoma cells through caspase 3-, 7-, and 8-dependent pathways, downregulation of the anti-apoptotic molecules survivin and cytochrome $c$, and caspase 9-independent apoptosis-inducing factor release from mitochondria. In addition, analyses of signaling pathway components demonstrated that mAb 3F8 strongly inhibited protein kinase B (Akt) and focal adhesion kinase activation and increased expression of cleaved PARP (105). There are three ongoing clinical studies of anti-GD2 mAbs in patients with metastatic melanoma (one study of ${ }^{131} \mathrm{I}-3 \mathrm{~F} 8 \mathrm{mAb}$ and two of $\mathrm{mAb}$ hu14.18K322A) listed in ClinicalTrials.gov.

\section{Other Anti-GD2 Targeted Therapies}

Although many patients with neuroblastoma have responded dramatically to treatment with anti-GD2 mAbs, $\sim 50 \%$ will relapse and not survive, and $20 \%$ do not respond to initial induction therapy following diagnosis and therefore may not be candidates for subsequent anti-GD2 mAbs under current treatment protocols (106). Other approaches to treatment that target disialoganglioside GD2 are needed for these patients. Anti-GD2 mAbs can be enhanced by conjugation with drugs, cytokines, NK cells, or radiolabeled compounds to deliver a potentially cytotoxic payload to tumors (Figure 2).

\section{Anti-GD2 CAR-T Cells}

Anti-GD2 chimeric antigen receptor $\mathrm{T}$ cells (CAR-T cells) can be engineered to recognize and target disialoganglioside GD2 on neuroblastoma cells, with the potential for greater durability and potency than anti-GD2 mAbs. CAR-T cells also have the ability to cross the blood-brain barrier, which may provide a clinical benefit against gliomas, but have been associated with severe central nervous system (CNS) toxicity involving $\mathrm{T}$-cell infiltration into brain regions known to contain disialoganglioside GD2 $(68,106,107)$. In neuroblastoma, initial clinical trials of first-generation anti-GD2 CAR-T cells, 
constructed primarily of Epstein Barr Virus-specific cytotoxic T lymphocytes with the scFv derived from dinutuximab (14g2a), produced some objective clinical responses (106). However, these responses were not reproduced by second-generation anti-GD2 CAR-T cells (68). Richman et al. compared the antitumor activity of anti-GD2 CAR-T cells derived from $14 \mathrm{~g} 2 \mathrm{a}$ with that of antiGD2 CAR-T cells derived from the E101K mutation of GD2 $\mathrm{scFv}$ in a human neuroblastoma xenograft in mice. Although the GD2-E101K mutation has enhanced antitumor activity in vivo, it was associated with extensive neuronal destruction in the mouse brain and encephalitis localized to the cerebellum and basal regions, which express GD2 in small quantities (107). GD2specific CAR and interleukin (IL)-15-expressing autologous NK T-cells currently are being studied in a phase I trial in children with relapsed or refractory high-risk neuroblastoma (ClinicalTrials.gov Identifier NCT03294954).

Mount et al. reported that patient-derived glioma cell cultures uniformly express disialoganglioside GD2 and found that antiGD2 CAR-T cells generated the antigen-dependent cytokines interferon- $\gamma$ and IL-2 and caused the death of diffuse midline glioma cells in vitro (108). Although anti-GD2 mAbs do not cross the blood-brain barrier, anti-GD2 CAR-T-cell therapy is being evaluated in two studies of patients with glioma. The first study (ClinicalTrials.gov Identifier NCT04099797) is scheduled to enroll 34 pediatric patients with high-grade GD2expressing gliomas or diffuse intrinsic pontine gliomas, whereas the second study (ClinicalTrials.gov Identifier NCT03252171) has enrolled 60 adult patients with GD2-positive gliomas. AntiGD2 CAR-T cells have also been studied in GD2-expressing Ewing sarcoma (109), glioblastoma (56), and retinoblastoma (62) and are being studied in osteosarcoma (ClinicalTrials.gov Identifier NCT02107963). Brown and Gargett are conducting a phase I study in Australia of the safety and immune effects of an escalating dose of autologous GD2 CAR-T cells in patients with GD2-expressing metastatic melanoma (110). Andersch et al. recently demonstrated in vitro that disialoganglioside GD2 is an effective target for CAR-T cell therapy in retinoblastoma (62). CAR-T cell therapy killed all 11 GD2-expressing cell lines studied. Seitz et al. reported that GD2-directed immunotherapy by GD2CAR-T can prevent metastasis in a highly aggressive mouse model of triple negative breast cancer (111).

\section{GD2 Vaccines}

The goal of vaccine-based immunotherapy is to produce a specific anti-tumor response directed against a specific tumor-associated antigen such as disialoganglioside GD2 (112). However, because most tumor-associated antigens are "self" antigens (i.e., idiotypic), presence of pre-existing immune tolerance against such idiotypic antigens is a barrier to effective active immunization with an idiotypic vaccine. On the other hand, anti-idiotypic vaccines utilize anti-idiotypic mAbs as surrogate antigens to avoid this problem and induce humoral and/or cellular immune antitumor responses against nonprotein tumor antigens. Although several preclinical studies using anti-idiotypic antibodies supported their utility as antitumor vaccines, human studies have been disappointing and anti-idiotypic vaccines have failed in later phase trials (113).
Bivalent vaccines containing neuroblastoma-associated antigens GD2 and GD3 together with the immunologic adjuvant OPT-821 have generated anti-GD2 and anti-GD3 IgG antibody responses in patients with neuroblastoma and currently are being studied in phase II trials $(66,114)$.

Carvajal et al. reported the results of a randomized, placebocontrolled phase II trial in which 136 patients with stage IV sarcoma received a trivalent vaccine against GD2, GD3, and GM2 or placebo plus the immunologic adjuvant OPT-821 (ClinicalTrials.gov Identifier NCT01141491) (115). At entry, 90\% of patients had relapsed disease and $14 \%$ had $\geq 4$ metastases resected. Induction of high IgG and IgM titers was observed in 52 and $24 \%$ of patients, respectively, receiving vaccine compared with 0 and $2 \%$ receiving placebo, but there was no significant difference in progression-free survival between the two groups.

\section{Novel Anti-GD2 Therapies}

In 2014, Ahmed and Cheung published a comprehensive review of novel approaches to anti-GD2 mAb-based immunotherapy for cancer, with the objectives of reducing tumor burden and curing neuroblastoma patients and patients with other solid tumors while lowering the dose and limiting the intensity of cytotoxic chemotherapy and radiotherapy (74). Cytokines are added to antibody treatment regimens to augment effector cell function but can also produce dose-limiting systemic side effects (116). Conjugation, or fusion, of cytokines to mAbs (immunocytokines) may avoid this issue, as, for example, Hu14.18-IL-2 anti-GD2 immunocytokine $(116,117)$. Other novel anti-GD2 therapies include targeted nanoparticles (presenting anticancer drugs at a sustained rate directly to tumor cells) (118), antibody-drug conjugates (allowing chemotherapeutic agents and other toxic drugs to be released into the microenvironment of the tumor via antibody targeting) (119), T-cell engaging bispecific antibodies (binding to two different antigens) (120), radiolabeled antibodies (delivering radiotherapy directly to the tumor environment) (121), and cell surface expression of chimeric antigen receptors (merging specific antigen binding with T-cell effector functions) (122). Barry et al. determined that the combination of dinutuximab and adoptively transferred ex vivo-activated human NK cells significantly improved the survival of immunodeficient mice following resection of neuroblastoma xenografts compared with dinutuximab or activated NK cells alone (123).

\section{SUMMARY AND CONCLUSIONS}

Unlike other gangliosides, which are expressed by most normal tissues, disialoganglioside GD2 expression is restricted to the CNS, peripheral sensory nerve fibers, dermal melanocytes, lymphocytes, and mesenchymal stem cells. Disialoganglioside GD2 is also expressed uniformly and abundantly by the vast majority of neuroblastomas, most melanomas and retinoblastomas, and many Ewing sarcomas, whereas its expression by SCLC, gliomas, osteosarcomas, and soft tissue sarcomas is more variable. Because it is expressed across a relatively broad range of tumor types, disialoganglioside GD2 can be considered a tumor-associated antigen and may promote a more malignant tumor phenotype through enhanced 
cell proliferation, growth, motility, migration, adhesion, and invasion. The expression profile of disialoganglioside GD2 and its role in cancer biology therefore provide a justification and rationale for clinical targeting of this antigen with antiGD2 mAbs and other therapeutic approaches. Anti-GD2 mAbs ch14.18 and ch14.18/CHO have been approved for the treatment of neuroblastoma. Clinical trials should clarify the role of anti-GD2 therapy in disialoganglioside GD2-expressing malignant tumors.

\section{AUTHOR CONTRIBUTIONS}

Conception by TO. Manuscript development, writing, and approval by TO, CI, and BN. All authors contributed to the article and approved the submitted version.

\section{REFERENCES}

1. Fleurence J, Fougeray S, Bahri M, Cochonneau D, Clémenceau B, Paris F, et al. Targeting $\mathrm{O}$-acetyl-ganglioside for cancer immunotherapy. J Immunol Res. (2017) 2017:5604891. doi: 10.1155/2017/5604891

2. Schnaar RL, Kinoshita T. Glycosphingolipids. In: Varki A, Cummings RD, Esko JD, editors. Essentials of Glycobiology. 3rd ed. Cold Spring Harbor, NY: Cold Spring Harbor Laboratory Press (2017), 125-35.

3. Christie WW. Gangliosides. The Lipid Web. Updated August 28. (2019). Available online at: www.lipidhome.co.uk/lipids/sphingo/gang/index.htm (accessed January 5, 2020).

4. Liu J, Zheng X, Pang X, Li L, Wang J, Yang C, et al. Ganglioside GD3 synthase (GD3S), a novel cancer drug target. Acta Pharmaceutica Sinica B. (2018) 8:713-20. doi: 10.1016/j.apsb.2018.07.009

5. Svennerholm L. Chromatographic separation of human brain gangliosides. $J$ Neurochem. (1963) 10:613-23. doi: 10.1111/j.1471-4159.1963.tb08933.x

6. Yu RK, Tsai Y-T, Ariga T, Yanagisawa M. Structures, biosynthesis, and functions of gangliosides-an overview. J Oleo Sci. (2011) 60:53744. doi: 10.5650/jos.60.537

7. Berois N, Osinaga E. Glycobiology of neuroblastoma: impact on tumor behavior, prognosis, and therapeutic strategies. Front Oncol. (2014) 4:114. doi: 10.3389/fonc.2014.00193

8. Lopez PHH, Schnaar Rl. Gangliosides in cell recognition and membrane protein regulation. Curr Opin Struct Biol. (2009) 19:549-57. doi: 10.1016/j.sbi.2009.06.001

9. Battula VL, Shi Y, Evans KW, Wang R-Y, Spaeth EL, Jacamo RO, et al. Ganglioside GD2 identifies breast cancer stem cells and promotes tumorigenesis. J Clin Invest. (2012) 122:2066-78. doi: 10.1172/JCI59735

10. Krengel U, Bousquet PA. Molecular recognition of gangliosides and their potential for cancer immunotherapies. Front Immunol. (2014) 5:325. doi: 10.3389/fimmu.2014.00325

11. Alvarez-Rueda N, Desselle A, Cochonneue D, Chaumette T, Clemenceau B, Leprieur S, et al. A monoclonal antibody to O-acetyl-GD2 ganglioside and not to GD2 shows potent anti-tumor activity without peripheral nervous system cross-reactivity. PLoS ONE. (2011) 6:e25220. doi: 10.1371/journal.pone.0025220

12. Cavdarli S, Groux-Degroot S, Delannoy P. Gangliosides: the doubleedge sword of neuro-ectodermal derived tumors. Biomolecules. (2019) 9:311. doi: 10.3390/biom9080311

13. Brodeur GM. Neuroblastoma: biological insights into a clinical enigma. Nat Rev Cancer. (2003) 3:203-16. doi: 10.1038/nrc1014

14. Yoshida S, Fukumoto S, Kawaguchi H, Sato S, Ueda R, Furukawa K. Ganglioside GD2 in small cell lung cancer cell lines: enhancement of cell proliferation and mediation of apoptosis. Cancer Res. (2001) 61:4244-52.

15. Navid F, Santana VM, Barfield RC. Anti-GD2 antibody therapy for GD2-expressing tumors. Curr Cancer Drug Targ. (2010) 10:200-9. doi: 10.2174/156800910791054167

\section{FUNDING}

The authors declare that editorial support provided by Omni Healthcare Communications was funded by United Therapeutics Corporation. The funder was not involved in the writing or editing of this review and did not influence its content. The funder was involved in the decision to submit for publication.

\section{ACKNOWLEDGMENTS}

Editorial support was provided by Omni Healthcare Communications. William Fiedelman, MD assisted with writing the manuscript and Carol Greco edited the manuscript. Neither William Fiedelman, MD nor Carol Greco met the ICMJE requirements for authorship.

16. Dobrenkov K, Cheung N-KV. GD2-targeted immunotherapy and radioimmunotherapy. Semin Oncol. (2014) 41:589612. doi: $10.1053 /$ j.seminoncol.2014.07.003

17. Yoshida S, Kawaguchi H, Sato S, Ueda R, Furukawa K. An anti-GD2 monoclonal antibody enhances apoptotic effects of anti-cancer drugs against small cell lung cancer cells via JNK (c-Jun terminal kinase) activation. JPN J Cancer Res. (2002) 93:816-24. doi: 10.1111/j.1349-7006.2002.tb01324.x

18. Chung T-W, Kim S-J, Choi H-J, Kim K-J, Kim M-J, Kim S-H, et al. Ganglioside GM3 inhibits VEGF/VEGFR-2-mediated angiogenesis: direct interaction of GM3 with VEGFR-2. Glycobiology. (2009) 19:22939. doi: $10.1093 /$ glycob/cwn114

19. Liu Y, Wondimu A, Yan S, Bob D, Ladisch S. Tumor gangliosides accelerate murine tumor angiogenesis. Angiogenesis. (2014) 17:56371. doi: $10.1007 /$ s10456-013-9403-4

20. Esaki N, Ohkawa Y, Hashimoto N, Tsuda Y, Ohmi Y, Bhuyian RH, et al. ASC amino acid transporter 2, defined by enzyme-mediated activation of radical sources, enhances malignancy of GD2-positive small-cell lung cancer. Cancer Sci. (2018) 109:141-53. doi: 10.1111/cas.13448

21. Zhang S, Cordon-Cardo C, Zhang HS, Sato S, Ueda R, Furukawa K. Selection of tumor antigens as targets for immune attack using immunohistochemistry: I. focus on gangliosides. Int J Cancer. (1997) 73:429. doi: 10.1002/(SICI)1097-0215(19970926)73:1<42::AID-IJC8>3.0.CO;2-1

22. Tong W, Maira M, Gagnon M, Saragovi HU. Ligands binding to cell surface ganglioside GD2 cause Src-dependent activation of N-Methyl-D-aspartate receptor signaling and changes in cellular morphology. PLoS ONE. (2015) 10:e0134255. doi: 10.1371/journal.pone.0134255

23. Yaghoubi S, Harrison T, Messerschmidt G, Corritori S. Dinutuximab binds specifically to disialoganglioside-2. Cancer Res. (2019) 79(Suppl. 13):543. doi: 10.1158/1538-7445.AM2019-543

24. Cheever MA, Allison JP, Ferris AS, Finn OJ, Hastings BM, Hecht TT, et al. The prioritization of cancer antigens: a National Cancer Institute pilot project for the acceleration of translational research. Clin Cancer Res. (2009) 15:5323-37. doi: 10.1158/1078-0432.CCR-09-0737

25. Mujoo K, Cheresh DA, Yang HM, Reisfeld RA. Disialoganglioside GD2 on human neuroblastoma cells: target antigen for monoclonal antibody-mediated cytolysis and suppression of tumor growth. Cancer Res. (1987) 47:1098-104.

26. Sariola H, Terävä H, Rapola J, Saarinen UM. Cell surface ganglioside GD2 in the immunohistochemical detection and differential diagnosis of neuroblastoma. Am J Clin Pathol. (1991) 96:248-52. doi: 10.1093/ajcp/96.2.248

27. Valentino I, Moss T, Olson E, Wang HJ, Elashoff R, Ladish S. Shed tumor gangliosides and progression of human neuroblastoma. Blood. (1990) 75:1564-7. doi: 10.1182/blood.V75.7.1564.bloodjournal7571564

28. Ladisch S, Wu ZL, Feig S, Ulsh L, Schwartz E, Floutsis G, et al. Shedding of GD2 ganglioside by human neuroblastoma. Int J Cancer. (1987) 39:73-6. doi: 10.1002/ijc.2910390113 
29. Balis FM, Busche C, Desai AV, Hibbitts E, Naranjo A, Bagatell R, et al. GD2 as a circulating tumor marker (CTB) for neuroblastoma (NBL). J Clin Oncol. (2018) 36(Suppl. 15):10538. doi: 10.1200/JCO.2018.36.15_suppl.10538

30. Schulz G, Cheresh DA, Varki NM, Yu A, Staffileno LK, Reisfeld RA. Detection of ganglioside GD2 in tumor tissues and sera of neuroblastoma patients. Cancer Res. (1984) 44:5914-20.

31. Wu Z-L, Schwartz E, Seeger R, Ladisch S. Expression of GD2 ganglioside by untreated primary human neuroblastomas. Cancer Res. (1986) 46:440-3.

32. Cheung N-KV, Lazarus H, Miraldi FD, Abramowsky CR, Kallick S, Saarinen $\mathrm{UM}$, et al. Ganglioside GD2 specific monoclonal antibody 3F8: a phase I study in patients with neuroblastoma and malignant melanoma. J Clin Oncol. (1987) 5:1430-40. doi: 10.1200/JCO.1987.5.9.1430

33. Schengrund C-L, Shochat SJ. Gangliosides in neuroblastomas. Neurochem Pathol. (1988) 8:189-202.

34. Yeh SDJ, Larson SM, Burch L, Kushner BH, Laquaglia MP, Finn R, et al. Radioimmunodetection of neuroblastoma with iodine-131-3F8: correlation with biopsy, iodine-131-metaiodobenzylguanidine and standard diagnostic modalities. J Nucl Med. (1991) 32:769-76.

35. Manenq C, Lesesve JF, Dreumont N, Massin F, Salignac S, Mansuy L, et al. Combined use of multiparametric flow cytometry and cytomorphology to enhance detection of neuroblastoma metastatic cells in bone marrow. Int $J$ Lab Hematol. (2020) 42:52-60. doi: 10.1111/ijlh.13137

36. Cheresh DA, Rosenberg J, Mujoo K, Hirschowitz L, Reisfeld RA. Biosynthesis and expression of the disialoganglioside GD2, a relevant target antigen on small cell lung carcinoma for monoclonal antibody-mediated cytolysis. Cancer Res. (1986) 46:5112-8.

37. Chen LC, Brown AB, Irene Y, Cheung NK, Kris MG, Krug LM. Analysis of GM2/GD2 synthase mRNA as a biomarker for small cell lung cancer. Lung Cancer. (2010) 67:216-20. doi: 10.1016/j.lungcan.2009.04.009

38. Grant SC, Kostakoglu L, Kris MG, Yeh SD, Larson SM, Finn RD, et al. Targeting of small-cell lung cancer using the anti-GD2 ganglioside monoclonal antibody 3f8: a pilot trial. Eur J Nucl Med. (1996) 23:1459. doi: 10.1007/BF01731837

39. Potapenko M, Shurin GV, de León J. Gangliosides as immunomodulators. Adv Exp Med Biol. (2007) 601:195-203. doi: 10.1007/978-0-387-72005-0_20

40. Hosain DM, Mohanty S, Ray P, Das T, Sa G. Tumor gangliosides and T cells: a deadly encounter. Front Biosci. (2012) 4:502-19. doi: 10.2741/s281

41. Dobrenkov K, Ostrovnaya I, Cheung IY, Feng Y, Cheung N-KV. GD2/GD3 expression: companion diagnostic for ganglioside-targeted immunotherapy against pediatric solid tumors. J Clin Oncol. (2016) 34(Suppl. 15):10567. doi: 10.1200/JCO.2016.34.15_suppl.10567

42. Cheresh DA, Klier FG. Diganglioside GD2 distributes preferentially into substrate-associated microprocesses on human melanoma cells during their attachment to fibronectin. J Cell Biol. (1986) 102:188797. doi: 10.1083/jcb.102.5.1887

43. Cheresh DA, Pierschbacher MD, Herzig MA, Mujoo K. Disialogangliosides GD2 and GD3 are involved in the attachment of human melanoma and neuroblastoma cells to extracellular matrix proteins. J Cell Biol. (1986) 102:688-96. doi: 10.1083/jcb.102.3.688

44. Ohmi Y, Kambe M, Ohkawa Y, Hamamura K, Tajima O, Takeuchi R, et al. Differential roles of gangliosides in malignant properties of melanomas. PLoS ONE. (2018) 13:e0206881. doi: 10.1371/journal.pone.0206881

45. Tsuchida T, Saxton RE, Morton DL, Irie RF. Gangliosides of human melanoma. Cancer. (1989) 63:1166-74. doi: 10.1002/10970142(19890315)63:6<1166::AID-CNCR2820630621>3.0.CO;2-5

46. Bailey K, Cost C, Davis I, Glade-Bender J, Grohar P, Houghton P, et al. Emerging novel agents for patients with advanced Ewing sarcoma: a report from the Children's Oncology Group (COG) New Agents for Ewing Sarcoma Task Force. F1000 Res. (2019) 8:493. doi: 10.12688/f1000research.18139.1

47. Casey DL, Lin T-Y, Cheung N-KV. Exploiting signaling pathways and immune targets beyond the standard of care for Ewing sarcoma. Front Oncol. (2019) 9:537. doi: 10.3389/fonc.2019.00537

48. Kailayangiri S, Alvatar B, Meltzer J, Pscherer S, Luecke A, Dierkes C, et al. The ganglioside antigen GD2 is surface-expressed in Ewing sarcoma and allows for MHC-independent immune targeting. Br J Cancer. (2012) 106:1123-33. doi: 10.1038/bjc.2012.57

49. Roth M, Linkowski M, Tarim J, Piperdi S, Sowers R, Geller D, et al. Ganglioside GD2 as a therapeutic target for antibody-mediated therapy in patients with osteosarcoma. Cancer. (2014) 120:54854. doi: $10.1002 / \mathrm{cncr} .28461$

50. Zhu W, Mao X, Wang W, Chen Y, Li D, Li H, et al. Anti-ganglioside GD2 monoclonal antibody synergizes with cisplatin to induce endoplasmic reticulum-associated apoptosis in osteosarcoma cells. Pharmazie. (2018) 73:80-6. doi: 10.1691/ph.2018.7836

51. Heiner JP, Miraldi F, Kallick S, Makley J, Neely J, Smith-Mensah WH, et al. Localization of GD2-specific monoclonal antibody 3F8 in human osteosarcoma. Cancer Res. (1987) 47:5377-81.

52. Butch ER, Mead PE, Amador Diaz V, Tillman H, Stewart E, Mishra JK, et al. Positron emission tomography detects in vivo expression of disialoganglioside GD2 in mouse models of primary and metastatic neuroblastoma. Cancer Res. (2019) 79:3112-24. doi: 10.1158/0008-5472.CAN-18-3340

53. Chang HR, Cordon-Cardo C, Houghton AN, Cheung NK, Brennan MF. Expression of disialogangliosides GD2 and GD3 on human soft tissue sarcomas. Cancer. (1992) 70:633-8. doi: 10.1002/10970142(19920801)70:3<633::AID-CNCR2820700315>3.0.CO;2-F

54. Saraf AJ, Dickman PS, Hingorani P. Disialoganglioside GD2 expression in pediatric rhabdomyosarcoma: a case series and review of the literature. J Pediatr Hematol Oncol. (2019) 41:118-20. doi: 10.1097/MPH.0000000000001311

55. Longee DC, Wikstrand CJ, Månsson JE, He X, Fuller GN, Bigner SH, et al. Disialoganglioside GD2 in neuroectodermal tumor cell lines and gliomas. Acta Neuropathol. (1991) 82:45-54. doi: 10.1007/BF00310922

56. Golinelli G, Grisendi G, Prapa M, Bestagno M, Spano C, Rossignoli $\mathrm{F}$, et al. Targeting GD2-positive neuroblastoma by chimeric antigen receptor empowered mesenchymal progenitors. Cancer Gene Ther. (2018). doi: 10.1038/s41417-018-0062-x. [Epub ahead of print].

57. Iwasawa $\mathrm{T}$, Zhang $\mathrm{P}$, Ohkawa $\mathrm{Y}$, Momota H, Wakabayashi T, Ohmi Y, et al. Enhancement of malignant properties of human glioma cells by ganglioside GD3/GD2. Int J Oncol. (2018) 52:1255-66. doi: 10.3892/ijo. 2018.4266

58. Portoukalian J, David MJ, Gain P, Richard M. Shedding of GD2 ganglioside in patients with retinoblastoma. Int J Cancer. (1993) 53:94851. doi: 10.1002/ijc.2910530614

59. Chantada GL, Rossi J, Casco F, Fandiño A, Scopinaro M, de Dávila MT, et al. An aggressive bone marrow evaluation including immunocytology with GD2 for advanced retinoblastoma. J Pediatr Hematol Oncol. (2006) 28:639-73. doi: 10.1097/00043426-200606000-00009

60. Shen H, Tang Y, Xu X, Tang H. Detection of the GD2+/CD56+/CD45immunophenotype by flow cytometry in cerebrospinal fluids from a patient with retinoblastoma. Pediatr Hematol Oncol. (2013) 30:302. doi: 10.3109/08880018.2012.737094

61. Sujjitjoon J, Atchaneeyasakul LS, Tsao S-T, Sayour E, Yenchitsomanus P-T, Chang L-J. GD2-specific chimeric antigen receptor T cells targeting retinoblastoma. Cancer Res. (2015) 75(Suppl. 15):3150. doi: 10.1158/1538-7445.AM2015-3150

62. Andersch L, Radke J, Klaus A, Schwiebert S, Winkler A, Schumann E, et al. CD171- and GD2-specific CAR-T cells potently target retinoblastoma cells in preclinical in vitro testing. BMC Cancer. (2019) 19:895. doi: 10.1186/s12885-019-6131-1

63. Orsi G, Barbolini M, Ficarra G, Tazzioli G, Manni P, Petrachi T, et al. GD2 expression in breast cancer. Oncotarget. (2017) 8:31592600. doi: 10.18632/oncotarget.16363

64. Mansoori M, Roudi R, Abbasi A, Abolhasani M, Abdi Rad I, Shariftabrizi A, et al. High GD2 expression defines breast cancer cells with enhanced invasiveness. Exp Mol Pathol. (2019) 109:25-35. doi: 10.1016/j.yexmp.2019.05.001

65. Vantaku V, Donepudi SR, Ambati CR, Jin F, Putluri V, Nguyen K, et al. Expression of ganglioside GD2, reprogram the lipid metabolism and EMT phenotype in bladder cancer. Oncotarget. (2017) 8:9562031. doi: 10.18632/oncotarget. 21038

66. Perez Horta Z, Goldberg JL, Sondel PM. Anti-GD2 and next generation mAb-based agents for cancer therapy. Immunotherapy. (2016) 8:1097117. doi: 10.2217/imt-2016-0021

67. Doronin II, Vishnyakova PA, Kholodenko IV, Ponomarev ED, Ryazantsev DY, Molotkovskaya IM, et al. Ganglioside GD2 in reception and 
transduction of cell death signal in tumor cells. BMC Cancer. (2014) 14:295. doi: 10.1186/1471-2407-14-295

68. Sait S, Modak SI. Anti-GD2 immunotherapy for neuroblastomas. Exp Rev Anticancer Ther. (2018) 17:889-904. doi: 10.1080/14737140.2017.1364995

69. Osinska I, Popko K, Demkow U. Perforin: an important player in immune response. Central Eur J Immunol. (2014) 39:109-15. doi: 10.5114/ceji.2014.42135

70. Siebert N, Seidel D, Eger C, Jüttner M, Lode HN. Functional bioassays for immune monitoring of high-risk neuroblastoma patients treated with ch14.18/CHO anti-GD2 antibody. PLoS ONE. (2014) 9:e107692. doi: 10.1371/journal.pone.0107692

71. Kholodenko IV, Kalinovsky DV, Doronin II, Deyev SM, Kholodenko RV. Neuroblastoma origin and therapeutic targets for immunotherapy. $J$ Immunol Res. (2018) 2018:7394268. doi: 10.1155/2018/7394268

72. Harding FA, Stickler MM, Razo J, Du Bridge RB. The immunogenicity of humanized and fully human antibodies. Residual immunogenicity resides in the CDR region. $m A B s$. (2010) 2:256-65. doi: 10.4161/mabs.2.3.11641

73. Cheung N-KV, Cheung IY, Kushner BH, Ostrovnaya I, Chamberlain E, Kramer K, et al. Murine anti-GD2 monoclonal antibody 3F8 combined with granulocyte-macrophage colony-stimulating factor and 13-cis-retinoic acid in high-risk patients with stage 4 neuroblastoma in first remission. J Clin Oncol. (2012) 30:3264-70. doi: 10.1200/JCO.2011.41.3807

74. Ahmed M, Cheung N-KV. Engineering anti-GD2 monoclonal antibodies for cancer immunotherapy. FEBS Lett. (2014) 588:288-97. doi: 10.1016/j.febslet.2013.11.030

75. Keyel ME, Reynolds CP. Spotlight on dinutuximab in the treatment of highrisk neuroblastoma: development and place in therapy. Biol Targ Ther. (2019) 13:1-12. doi: 10.2147/BTT.S114530

76. Soman G, Kallarkal AT, Michiel D, Yang X, Saptharishi N, Jiang $\mathrm{H}$, et al. Analytical characterization of ch14.18: a mouse-human chimeric disialoganglioside-specific therapeutic antibody. mABs. (2012) 4:84-100. doi: 10.4161/mabs.4.1.18566

77. Mujoo K, Kipps TJ, Yang HM, Cheresh DA, Wargalla U, Sander DJ, et al. Functional properties and effect on growth suppression on human neuroblastoma tumors by isotype switch variants of monoclonal antiganglioside GD2 antibody 14.18. Cancer Res. (1989) 49:2857-61.

78. Mueller B, Romerdahl CA, Gillies SD, Reisfeld RA. Enhancement of antibody-dependent cytotoxicity with chimeric anti-GD2 antibody. $J$ Immunol. (1990) 144:1382-6.

79. Dhillon S. Dinutuximab: first global approval. Drugs. (2015) 75:9237. doi: 10.1007/s40265-015-0399-5

80. Pennington B, Ren S, Barton S, Bacelar M, Edwards SJ. Dinutuximab beta for treating neuroblastoma: an evidence review group and decision support unit perspective of a NICE single technology appraisal. Pharmacoeconomics. (2019) 37:985-93. doi: 10.1007/s40273-018-0744-0

81. Ladenstein R, Pötschger U, Valteau-Couanet D, Luksch R, Castel V, Yaniv I, et al. Interleukin 2 with anti-GD2 antibody ch14.18/CHO (dinutuximab beta) in patients with high-risk neuroblastoma (HR-NBL1/SIOPEN): a multicentre, randomised, phase 3 trial. Lancet Oncol. (2018) 19:161729. doi: 10.1016/S1470-2045(18)30578-3

82. Kushner BH, Cheung IY, Modak S, Basu EM, Roberts SS, Cheung $\mathrm{N}-\mathrm{K}$. Humanized 3F8 anti-GD2 monoclonal antibody dosing with granulocyte-macrophage colony-stimulating factor in patients with resistant neuroblastoma. a phase 1 clinical trial. JAMA. (2018) 4:1729-35. doi: 10.1001/jamaoncol.2018.4005

83. Kholodenko IV, Kalinovsky DV, Svirshchevskaya EV, Doronin II, Kolonalova $\mathrm{MV}$, Kibardin AV, et al. Multimerization through pegylation improves pharmacokinetic properties of scFv fragments of GD2-specific antibodies. Molecules. (2019) 24:3835. doi: 10.3390/molecules24213835

84. Furman WL, Federico SM, McCarville MB, Shulkin BL, Davidoff AM, Krasin MJ, et al. A phase II trial of Hu14.18K322A in combination with induction chemotherapy in children with newly diagnosed high-risk neuroblastoma. Clin Cancer Res. (2019) 25:6320-8. doi: 10.1158/1078-0432.CCR-19-1452

85. Mora J. Dinutuximab for pediatric patients with high-risk neuroblastoma. Exp Rev Clin Pharmacol. (2016) 9:64753. doi: 10.1586/17512433.2016.1160775

86. Yu AL, Gilman AL, Ozkaynak MF, London WB, Kreissman SG, Chen HX, et al. Anti-GD2 antibody with GM-CSF, interleukin-2, and isotretinoin for neuroblastoma. N Engl J Med. (2010) 363:132434. doi: 10.1056/NEJMoa0911123

87. Batova A, Kamps A, Gillies SD, Reisfeld RA, Yu AL. The ch14.18-GMCSF fusion protein is effective at mediating antibody-dependent cellular cytotoxicity and complement-dependent cytotoxicity in vitro. Clin Cancer Res. (1999) 5:4259-63.

88. Agarwal S, Lakoma A, Chen Z, Hicks J, Metelitsa LS, Kim ES, et al. GCSF promotes neuroblastoma tumorigenicity and metastasis via STAT3dependent cancer stem cell activation. Cancer Res. (2015) 75:256679. doi: 10.1158/0008-5472.CAN-14-2946

89. Zhang C, Xiong X, Li Y, Huang K, Liu L, Peng X, et al. Cytokine-induced killer cells/natural killer cells combined with anti-GD2 monoclonal antibody increase cell death rate in neuroblastoma SK-N-SH cells. Oncol Lett. (2019) 18:6525-35. doi: 10.3892/ol.2019.11020

90. Liu Y, Wu H-W, Sheard MA, Sposto R, Somanchi SS, Cooper LJN, et al. Growth and activation of natural killer cells ex vivo from children with neuroblastoma for adoptive cell therapy. Clin Cancer Res. (2013) 19:213243. doi: 10.1158/1078-0432.CCR-12-1243

91. Balis FM, Busche C, Desai AV, Hibbitts E, Naranjo A, Bagatell R, et al. The ganglioside GD2 as a circulating tumor biomarker for neuroblastoma. Pediatr Blood Cancer. (2020) 67:e28031. doi: 10.1002/pbc.28031

92. Terzic T, Cordeau M, Herblot S, Teira P, Cournoyer S, Beaunoyer M, et al. Expression of disialoganglioside (GD2) in neuroblastic tumors: a prognostic value for patients treated with anti-GD2 immunotherapy. Pediatr Dev Pathol. (2018) 21:355-62. doi: 10.1177/1093526617723972

93. Uttenreuther-Fischer MM, Huang CS, Yu AL. Pharmacokinetics of human-mouse chimeric anti-GD2 $\mathrm{mAb}$ ch14.18 in a phase I trial in neuroblastoma patients. Cancer Immunol Immunother. (1995) 41:3318. doi: 10.1007/BF01526552

94. Handgretinger R, Anderson K, Lang P, Dopfer R, Klingebiel T, Schrappe $\mathrm{M}$, et al. A phase I study of human/mouse chimeric antiganglioside GD2 antibody CH14.18 in patients with neuroblastoma. Eur J Cancer. (1995) 31A:261-7. doi: 10.1016/0959-8049(94)00413-Y

95. Ozkaynak MF, Sondel PM, Krailo MD, Gan J, Javorsky B, Reisfeld RA, et al. Phase I study of chimeric human/murine anti-ganglioside G(D2) monoclonal antibody (ch14.18) with granulocyte-macrophage colony-stimulating factor in children with neuroblastoma immediately after hematopoietic stem-cell transplantation: a Children's Cancer Group Study. J Clin Oncol. (2000) 18:4077-85. doi: 10.1200/JCO.2000.18. 24.4077

96. Simon T, Hero B, Faldum A, Handgretinger R, Schrappe M, Niethammer D, et al. Consolidation treatment with chimeric anti-GD2-antibody ch 14.18 in children older than 1 year with metastatic neuroblastoma. J Clin Oncol. (2004) 22:3549-57. doi: 10.1200/JCO.2004.08.143

97. Ari P, Kars M, Meany H, Pestieau S. Treatment of transient peripheral neuropathy during chimeric 14.18 antibody therapy in children with neuroblastoma: a case series. J Pediatr Hematol Oncol. (2018) 40:e1136. doi: 10.1097/MPH.0000000000000889

98. Mody R, Naranjo A, Van Ryn C, Yu AL, London WB, Shulkin BL, et al. Irinotecan-temozolomide with temsirolimus or dinutuximab in children with refractory or relapsed neuroblastoma (COG ANBL1221): an open-label, randomised, phase 2 trial. Lancet Oncol. (2017) 18:94657. doi: 10.1016/S1470-2045(17)30355-8

99. Tran HC, Wan Z, Sheard MA, Sun J, Jackson JR, Malvar J, et al. TGF $\beta$ R1 blockade with galunisertib (LY2157299) enhances anti-neuroblastoma activity of anti-GD2 antibody dinutuximab (ch14.18) with natural killer cells. Clin Cancer Res. (2017) 23:804-13. doi: 10.1158/1078-0432.CCR-16-1743

100. Vanichapol T, Chutipongtanate S, Anurathapan U, Hongeng S. Immune escape mechanisms and future prospects for immunotherapy in neuroblastoma. Biomed Res Int. (2018) 2018:1812535. doi: 10.1155/2018/1812535

101. Peinemann F, van Dalen EC, Enk H, Tytgat GA. Anti-GD2 antibodycontaining immunotherapy postconsolidation therapy for people with high-risk neuroblastoma treated with autologous haematopoietic stem cell transplantation. Cochrane Database Syst Rev. (2019) 4:CD012442. doi: 10.1002/14651858.CD012442.pub2

102. Aixinjueluo W, Furukawa K, Zhang Q, Hamamura K, Tokuda N, Yoshida S, et al. Mechanisms for the apoptosis of small cell lung cancer cells induced 
by anti-GD2 monoclonal antibodies. Roles of anoikis. J Biol Chem. (2005) 280:29828-36. doi: 10.1074/jbc.M414041200

103. Edelman MJ, Juan O, Navarro A, Golden G, Saunders A. Feasibility of outpatient dinutuximab (D) and irinotecan (I) for second-line treatment of relapsed or refractory small cell lung cancer (RR SCLC): part 1 of an open-label, randomized, phase 2/3 study. J Thorac Oncol. (2018) 13(Suppl. 4):S48. doi: 10.1016/S1556-0864(18)30363-0

104. Press Release. United Therapeutics Announces Study of Unituxin ${ }^{\circledR}$ (Dinutuximab) for Small Cell Lung Cancer Did Not Meet Primary Endpoint. Avaliable online at: https://ir.unither.com/file/Index?KeyFile=402605171 (accessed February 3, 2020).

105. Tsao C-Y, Sabbatino F, Cheung N-KV, Hsu JC-f, Villani V, Wang X, et al. Anti-proliferative and pro-apoptotic activity of GD2 ganglioside-specific monoclonal antibody 3F8 in human melanoma cells. Oncoimmunology. (2015) 4:e1023975. doi: 10.1080/2162402X.2015.1023975

106. Richards RM, Sotillo E, Majzner RG. CAR T cell therapy for neuroblastoma. Front Immunol. (2018) 9:2380. doi: 10.3389/fimmu.2018.02380

107. Richman SA, Nunez-Cruz S, Moghimi B, Li LZ, Gershenson GT, Mourelatos $Z$, et al. High-affinity GD2-specific CAR T cells induce fatal encephalitis in a preclinical neuroblastoma model. Cancer Immunol Res. (2018) 6:3646. doi: 10.1158/2326-6066.CIR-17-0211

108. Mount CW, Majzner RG, Sundaresh S, Kadapakkam M, Haile S, Labanieh L, et al. Potent antitumor efficacy of anti-GD2 CAR-T cells in H3K27M+ diffuse midline gliomas. Nat Med. (2018) 24:5729. doi: 10.1038/s41591-018-0006-x

109. Charan M, Dravid P, Cam M, Audino A, Gross AC, Arnold MA, et al. GD2-directed CAR-T cells in combination with HGF-targeted neutralizing antibody (AMG102) prevent primary tumor growth and metastasis in Ewing sarcoma. Int J Cancer. (2019) 146:3184-95. doi: 10.1002/ijc.32743

110. Brown M, Gargett T. CARPETS: a phase I study of the safety and immune effects of an escalating dose of autologous GD2 chimeric antigen receptor-expressing peripheral blood T cells in patients with GD2-positive metastatic melanoma and refractory solid tumors. Cancer Res. (2019) 79(Suppl). doi: 10.1158/1538-7445.AM2019-CT118

111. Seitz CM, Schroeder S, Knopf P, Krahl A-C, Hau J, Schleicher S, et al. GD2-targeted chimeric antigen receptor $\mathrm{T}$ cells prevent metastasis formation by elimination of breast cancer stem-like cells. Oncoimmunology. (2019) 9:e1683345. doi: 10.1080/2162402X.2019.1683345

112. Ladjemi MZ. Anti-idiotypic antibodies as cancer vaccines: achievements and future improvements. Front Oncol. (2012) 2:158. doi: $10.3389 /$ fonc. 2012.00158

113. Kohler H, Pashov A, Kieber-Emmons T. The promise of anti-idiotype revisited. Front Immunol. (2019) 10:808. doi: 10.3389/fimmu.2019.00808

114. Kushner BH, Cheung IY, Modak S, Kramer K, Ragupathi G, Cheung NKV. Phase I trial of a bivalent ganglioside vaccine in combination with b-glucan. Clin Cancer Res. (2014) 20:1375-82. doi: 10.1158/1078-0432.CCR-13-1012

115. Carvajal RD, Agulnik M, Ryan CW, Milhem MM, George S, Lewis R, et al. Trivalent ganglioside vaccine and immunologic adjuvant versus adjuvant alone in metastatic sarcoma patients rendered disease-free by surgery: a randomized phase 2 trial. J Clin Oncol. (2014) 32(Suppl. 15):10520. doi: 10.1200/jco.2014.32.15_suppl.10520
116. Vincent M, Quéméner A, Jacques Y. Antitumor activity of an immunocytokine composed of an anti-GD2 antibody and the IL-15 superagonist RLI. Oncoimmunology. (2013) 2:e26411. doi: 10.4161/onci.26441

117. Shusterman S, Naranjo A, Van Ryn C, Hank JA, Parisi MT, Shulkin BL, et al. Antitumor activity and tolerability of hul4.18-IL2 with GMCSF and isotretinoin in recurrent or refractory neuroblastoma: a Childrens Oncology Group phase II study. Clin Cancer Res. (2019) 25:604451. doi: 10.1158/1078-0432.CCR-19-0798

118. Tivnan A, Heilinger T, Ramsey JM, O'Connor G, Pokomy JL, Sarkaria JN, et al. Anti-GD2-ch14.18/CHO coated nanoparticles mediate glioblastoma (GBM)-specific delivery of the aromatase inhibitor, letrozole, reducing proliferation, migration and chemoresistance in patient-derived GBM tumor cells. Oncotarget. (2017) 8:16605-20. doi: 10.18632/oncotarget. 15073

119. Suzuki M, Cheung N-KV. Disialoganglioside GD2 as a therapeutic target for human diseases. Exp Opin Ther Targets. (2015) 19:34962. doi: $10.1517 / 14728222.2014 .986459$

120. Cheal SM, Xu H, Guo HF, Zanzonico PB, Larson SM, Cheung NK. Preclinical evaluation of multistep targeting of disialoganglioside GD2 using an IgG-scFv bispecific antibody with high affinity for GD2 and DOTA metal complex. Mol Cancer Ther. (2014) 13:180312. doi: 10.1158/1535-7163.MCT-13-0933

121. Cheung N-KV, Landmeier B, Neeley J, Nelson AD, Abromowsky C, Ellery S, et al. Complete tumor ablation with iodine 131-radiolabeled disialoganglioside GD2-specific monoclonal antibody against human neuroblastoma xenografted in nude mice. J Nat Cancer Inst. (1986) 77:73945. doi: 10.1093/jnci/77.3.739

122. Xu X, Huang W, Heczey A, Liu D, Guo L, Wood MS, et al. NKT cells co-expressing a GD2-specific chimeric antigen receptor and IL-15 show enhanced in vivo persistence and antitumor activity against neuroblastoma. Clin Cancer Res. (2019) 25:7126-38. doi: 10.1158/1078-0432.CCR-19-0421

123. Barry WE, Jackson JR, Asuelime GE, Wu H-W, Sun J, Wan Z, et al. Activated natural killer cells with anti-GD2 antibody dinutuximab improves survival of mice after surgical resection of primary neuroblastoma. Clin Cancer Res. (2019) 25:325-33. doi: 10.1158/1078-0432.CCR-18-1317

Conflict of Interest: TO declares research funding (to institution) from United Therapeutics Corp.

The remaining authors declare that the research was conducted in the absence of any commercial or financial relationships that could be construed as a potential conflict of interest.

Copyright (0) 2020 Nazha, Inal and Owonikoko. This is an open-access article distributed under the terms of the Creative Commons Attribution License (CC BY). The use, distribution or reproduction in other forums is permitted, provided the original author(s) and the copyright owner(s) are credited and that the original publication in this journal is cited, in accordance with accepted academic practice. No use, distribution or reproduction is permitted which does not comply with these terms. 